\title{
Dendritic Spines of Rat Cerebellar Purkinje Cells: Serial Electron Microscopy with Reference to Their Biophysical Characteristics
}

\author{
Kristen M. Harris ${ }^{1}$ and John K. Stevens ${ }^{2}$ \\ 'Department of Neurology, Children's Hospital, Boston, Massachusetts 02115, and PPlayfair Neuroscience Unit, University \\ of Toronto, Toronto, Ontario M5T 2S8, Canada
}

\begin{abstract}
We have used serial electron microscopy and 3-dimensional reconstructions of dendritic spines from Purkinje spiny branchlets of normal adult rats to evaluate 2 questions about the relationships of spine geometry to synaptic efficacy. First, do relationships between spine geometry and other anatomical indicators of synaptic activity suggest that spine size and shape might be associated with synaptic efficacy? Reconstructed spines were graphically edited into head and neck compartments; the area of the postsynaptic density (PSD) was measured; the volume of spine smooth endoplasmic reticulum (SER) was computed; and all of the vesicles in the axonal varicosities were counted. Spine head volume and the volume of SER contained in the head are well correlated with the area of the PSD and the number of vesicles in the presynaptic axonal varicosity. Spine neck diameter does not fluctuate with PSD area, head volume, or the vesicle number. These results suggest that the dimensions of the spine head, but not of the spine neck, are likely to reflect differences in synaptic efficacy.

Second, does the geometry of cerebellar spine necks reduce the transfer of synaptic charge to the recipient dendrite from the theoretical maximum that could be transferred if the synapse were on a dendritic shaft? Comparison of volume to surface area showed that the spine heads are approximately spherical and the necks are approximately cylindrical. Application of results from a biophysical model that assumed these geometrical shapes for spines (Wilson, 1984) showed that the cerebellar spine necks are unlikely to reduce transfer of synaptic charge by more than $5-20 \%$ even if their SER were to completely block passage of current through the portion of the neck that it occupies. We suggest that the constricted spine neck diameter might serve to isolate metabolic events in the vicinity of activated synapses
\end{abstract}

\footnotetext{
Received Jan. 14, 1988; revised Apr. 21, 1988; accepted Apr. 22, 1988.

We thank Ms. Judy Trogadis for training K.M.H. on the movie reconstruction system and for many interesting discussions. Dr. D. Max Snodderly and Dr. Thomas Brown are appreciated for their insightful discussions of the results. Dr. Richard Sidman and Dr. Daniel Johnston are thanked for their improvements of an earlier version of the manuscript. We are grateful to Ms. Linda Kirschner and Mr. Nariman Shambayati for writing the software system used to display and edit the 3-dimensional reconstructions in the Image Graphics Laboratory (IGL) at Children's Hospital. We thank Beatrice Tsao for her help with some of the graphics editing. This work was supported by the Alfred P. Sloan Foundation and NIH Grant NS21184 (K.M.H.), MRC Grant MT7345 (J.K.S.), and NIH Grant NS20820 (R. L. Sidman, P.I.) and by MR Center Grant P30-HD18655 from NICHD.

Correspondence should be addressed to Kristen M. Harris, Ph.D., Department of Neurology, Enders 2, Children's Hospital, 300 Longwood Avenue, Boston, MA 02115 .

Copyright (C) 1988 Society for Neuroscience $0270-6474 / 88 / 124455-15 \$ 02.00 / 0$
}

by reducing diffusion to neighboring synapses, without significantly influencing the transfer of synaptic charge to the postsynaptic dendrite.

Dendritic spines have captured the imagination of neuroscientists since the turn of the century when Ramón y Cajal (1891, 1911) first described them on Golgi-impregnated neurons and proposed that they might be sites of communication between neurons. With study by electron microscopy, it has been established that spines are indeed major postsynaptic targets of excitatory axonal input (Gray, 1959). Because of their small size, spines have remained inaccessible to direct study by electrophysiological methods. Therefore, biophysical models have been developed to test the range of possible effects that spines might have on transfer of information between neurons (Chang, 1952; Diamond et al., 1970; Rall, 1970, 1974, 1978; Carnavale and Johnston, 1982; Perkel, 1982/83; Johnston and Brown, 1983; Koch and Poggio, 1983; Kawato et al., 1984; Turner, 1984; Wilson, 1984; Coss and Perkel, 1985; Perkel and Perkel, 1985; Brown et al., 1988). If spine heads have excitable membrane, then the size of the action potential generated in the spine head is nonlinearly related to the spine neck resistance (Jack et al., 1975; Rall and Segev, 1988), and groups of neighboring spines might serve logical gating functions (Miller et al., 1985; Shepherd et al., 1985; Shepherd and Brayton, 1987). A major conclusion drawn from these biophysical models is that within an optimal range, small changes in the dimensions of the spine neck could have large effects on the amount of synaptic current generated in spine heads (for both passive and active spines) and the amount of charge transferred to the recipient dendrite. Other theoretical work suggests that the constricted spine necks might facilitate formation of an electrochemical gradicnt that attracts charged molecules into the spine head from the dendrite (Horwitz, 1984), control the diffusion of substances into and out of the spine (Shepherd, 1979), or enhance the elevation of calcium concentration in the vicinity of activated synapses on spine heads (Gamble and Koch, 1987).

Several anatomical studies have shown that spine morphology is responsive to experimental manipulations and environmental conditions. Many of these studies have used observations from Golgi-impregnated neurons and therefore have been limited by the resolution of the light microscope from making complete measurements of dendritic spines and their associated synapses (e.g., Scheibel and Scheibel, 1968; Schapiro and Vukovitch, 1970; Valverde, 1971; Globus et al., 1973; Ryugo et al., 1975; Rutledge, 1976; Feldman and Peters, 1979; Pysh and Weiss, 1979; Connor et al., 1980; Coss et al., 1980; Rausch and Scheich, 
1982). Other investigators have measured parts of spines in electron micrographs of single thin sections and used stereological procedures to reveal stimulation-induced changes in spine size and/or synaptic area (e.g., Van Harreveld and Fifkova, 1975; Moshkov, 1977, 1980; Lee et al., 1980; Fifkova and Anderson, 1981; Vrensen and Nunes-Cardozo, 1981; Desmond and Levy, 1983, 1986a, b; Chang and Greenough, 1984; Wenzel et al., 1985; Petukhov and Popov, 1986). Interpretation of these results has been difficult because most of the spine structure and synaptic area are not visible on a single thin section (Harris and Stevens, 1988) and because of differences in tissue preparation protocols (Desmond and Levy, 1988).

In order to overcome the limitations of light microscopy and single thin section analysis, spines and synapses have been studied with serial electron microscopy (e.g., Westrum and Blackstad, 1962; Freire, 1978; Spacek and Hartman, 1983; Wilson et al., 1983; Spacek, 1985; Reeves and Steward, 1986; Benshalom and White, 1988). Tracings of spine parts from sequential electron micrographs were used to depict the spines in 3 dimensions by artistic representations or computer-generated graphical reconstructions and to obtain quantitative measures of some spine features.

We have used serial electron microscopy and computer-assisted reconstruction systems to obtain sufficiently complete and accurate measures of dendritic spines, their smooth endoplasmic reticulum (SER), synapses, and presynaptic varicosities to begin evaluating 2 questions concerning the possible effects of spine geometry on synaptic efficacy. First, does spine neck constriction serve to partition an appropriate amount of SER and cytoplasm in the vicinity of the synapse, thus providing a mechanism for local metabolic control of the synapse and separation of biochemical events occurring at activated synapses from events occurring at neighboring inactive synapses ("compartmentation" hypothesis)? The word "compartmentation" was chosen instead of "compartmentalization" because compartmentation simply means division into separate sections or units, where compartmentalization suggests division especially into units lacking normal interaction or cooperation. Since we do not know whether neighboring spines might act as electronic or electrically active logical units, compartmentation is used here. Second, is there sufficient variation in spine neck dimensions to suggest that alterations in spine neck resistance could provide a simple mechanism for modulating the transfer of synaptic charge to the recipient dendrite, and hence modulate synaptic efficacy ("rcsistancc" hypothesis)?

Spiny branchlets of cerebellar Purkinje cells were chosen for our first analysis because previous study revealed that these spines were of relatively more uniform shape than spines found in hippocampus (Harris and Landis, 1986) or cerebral cortex (Jones and Powell, 1969; Peters and Kaiserman-Abramhof, 1970), and therefore principles governing spine shape and size might be easier to discern. A subsequent paper will provide a comparative analysis for hippocampal dendritic spines (K. M. Harris and J. K. Stevens, unpublished observations). Preliminary results have been reported elsewhere (Harris et al., 1985; Harris and Stevens, 1986, 1988).

\section{Materials and Methods}

\section{Tissue preparation}

Two male rats of the Long-Evans strain (137 and $310 \mathrm{gm}$ ) were perfused through the heart under deep pentobarbital anesthesia with $2 \%$ paraformaldehyde and $2.5 \%$ glutaraldehyde in $0.1 \mathrm{~m}$ cacodylate buffer at
$\mathrm{pH} 7.35,37^{\circ} \mathrm{C}$ and $4 \mathrm{psi}$. The brains were left undisturbed in the cranium for $1 \mathrm{hr}$ and then the cerebellum was removed. For the first animal, the whole cerebellum was postfixed in the aldehyde mixture for $2 \mathrm{hr}$ at $4^{\circ} \mathrm{C}$ and then stored in $0.1 \mathrm{~m}$ cacodylate buffer for $2 \mathrm{~d}$. Then it was removed from buffer and sliced sagittally at $400 \mu \mathrm{m}$. The slices were washed in cacodylate buffer, soaked for $1 \mathrm{hr}$ in $1 \% \mathrm{OsO}_{4}$, washed in cacodylate and acetate buffers, soaked overnight in $1 \%$ uranyl acetate at $4^{\circ} \mathrm{C}$, rinsed in acetate buffer, dehydrated through graded ethanols, propylene oxide, embedded in Epon, and serially sectioned at silver-gray $(0.06 \mu \mathrm{m})$ on a Reichert Ultracut E ultramicrotome (series 20). For the second animal, the cerebellum was sliced sagittally at $400 \mu \mathrm{m}$, immediately after dissection. These slices were then washed with agitation in buffer, soaked for $1 \mathrm{hr}$ in $1.5 \%$ potassium ferrocyanide with $1 \% \mathrm{OsO}_{4}$, followed by 1 $\mathrm{hr}$ in $1 \% \mathrm{OsO}_{4}$. Tissue sections were soaked in 30 and $50 \%$ ethanol for $10 \mathrm{~min}$ each, immersed for $1 \mathrm{hr}$ in $1 \%$ uranyl acetate in $70 \%$ ethanol at room temperature, dehydrated and embedded in Epon, and serially thin sectioned at silver (about $0.07 \mu \mathrm{m}$, series 25 ). The series identification numbers reflect that these are the 20th and 25 th series that have been photographed in the laboratory, including all studies of hippocampus and cerebellum. Both series were mounted on Formvar-coated slot grids (Synaptek) and stained for 5 min with Reynolds' lead citrate. Each grid of each series was mounted in a grid cassette (Stevens and Trogadis, 1984) and stored in a numbered gelatin capsule.

\section{Electron microscopy}

The grid cassettes were mounted in rotating stages to obtain consistent orientation of sections on adjacent grids during photography at a JEOL 100B electron microscope. Two segments of Purkinje cell spiny branchlets werc photographed at $100 \mathrm{kV}$ and at 10,000 and 15,000 magnification. For the first animal, a segment of spiny branchlet was photographed and analyzed through 42 serial sections. For the second animal, a segment of spiny branchlet dendrite was photographed through 150 serial sections and quantitatively analyzed through 50 serial sections. We chose to photograph these 2 dendritic segments through serial sections instead of selecting a large population of individual spines from different dendrites for 2 practical reasons. First, this approach allowed us to choose a magnification low enough $(10,000)$ to contain the dendrites, all of their associated spines, and their presynaptic axonal varicosities on a single EM negative but high enough to retain excellent resolution of the organelles, vesicles, and postsynaptic densities. By positioning the cross-sectioned dendrite in the very center of the field on each serial section, we could avoid the very tedious process of trying to reconstruct from montaged series. To obtain the same number of spines from a larger population of dendrites would have required photographing several different fields through serial sections or a single field at a very much lower magnification, which would have compromised the accuracy of the reconstructions. This method was unbiased because the properties of dendritic spines in preceding and succeeding sections could not be known, whereas choosing individual spines would be subject to the experimenter's ability to identify portions of spines on single sections.

\section{Three-dimensional reconstructions}

The EM negatives were rephotographed onto positive $35 \mathrm{~mm}$ filmstrips to create a continuous "movie" of the serial sections (Stevens, 1980; Stevens et al., 1980; Stevens and Trogadis, 1984). The filmstrip was mounted on a computer-controlled film transport system and viewed through a high-resolution TV camera. To align subjects in adjacent sections, the image in the first section was stored in a frame buffer, and the filmstrip was advanced to the next section where the same subject was viewed "live" with the camera. The live and stored images were flashed back and forth on a high-resolution monitor, and the film transport system was moved until the live image of the subject and all of the surrounding structures were superimposed on the stored images from the adjacent scetion. The coordinates of the aligned images were then stored by the computer. This process of microalignment was repeated independently for each sectioned portion of the dendrite, all dendritic spines, their SER, their synapses, and their presynaptic axonal varicosities. Once portions of individual subjects were microaligned across serial sections, a bitpad was used to superimpose the trace on the membrane boundaries or a spot to count individual vesicles in the presynaptic axonal varicosity. To calculate total length of the dendritic segments, a cursor was positioned in the center of the dendritic profile and lengths added to retain this central position when passing through aligned adjacent sections using the MENS program (Stevens and Trogadis, 1984). 
When the tracings were complete, they were stored on floppy disks and transported to the Image Graphics Laboratory (IGL) at Children's Hospital, where programs were developed to read the data structure of the traces so that a modified version of the PANDORA image-analysis system (Pearlstein et al., 1986) could be used to display, edit, and analyze the reconstructions quantitatively.

\section{Graphics editing}

The tracings of the dendritic spines were graphically removed at their origins from the dendritic segments and then edited into their heads and necks. The neck was considered to be the portion of the dendritic spine that was of approximately uniform diameter along the length between the spine origin and the inflexion with the head. To discern where to cut the junction between the head and the neck graphically, each reconstructed spine was first rotated about its central axis to view the spine from all angles. Then front $\left(0^{\circ}\right)$ and back $\left(180^{\circ}\right)$ views were plotted with hidden lines supressed to serve as guides for editing individual traces of each portion of the spine in each section. Similarly, the SER in each spine was edited into the head and neck portions. The edited spines were replotted with hidden lines supressed to discern that they were correctly edited at the head-neck and neck-dendrite junctions. If these plots revealed editing errors, the spines were re-edited until all junctions were correct. Then spine dimensions were measured and computed as described below.

\section{Computation of volumes, areas, lengths, and counts}

Spine neck and head volumes. These were computed by multiplying the area of traced cytoplasm by the section thickness and adding a cross section containing portions of the spines. The boundary areas of spines appear as gray fuzz on sections where spines were cut parallel to their plasmalemma. To compute the volume associated with these spine boundaries, the area of the gray fuzz was measured, multiplied by section thickness, and divided by 2 , assuming that approximately half of the gray fuzz area is adjacent to cytoplasm. Total spine volume was computed by adding the volumes of each of the head and neck compartments together.

Total PSD areas. For cross-sectioned synapses, total PSD areas were computed by summing the lengths of the PSD and multiplying by section thickness and the number of sections. For synapses cut en face (i.e., parallel to the PSD), the area of the PSD was measured on the single section in which it appeared. When a synapse was cut obliquely, some portions were cut parallel to the PSD on adjacent sections. A "connector" length was constructed where the edges of the 2 areas overlapped on adjacent sections and multiplied by section thickness to calculate the amount of PSD area crossing obliquely between the 2 adjacent sections. This "connector" area was added to areas cut en face or in cross section along an oblique or curving synaptic surface.

Spine neck length was measured between the dendrite and junction with the head, across serial sections for cross-sectioned necks, and within a single section for longitudinally sectioned necks. Spine head length was determined from the calculation of head diameter described under Biophysical Modeling below. Total spine length was calculated by adding the measured neck length to the calculated head length.

Spine neck diameter was first measured at the thinnest part of the neck using superimposed sections of the neck as guides. The average radius of the neck along its length was also computed from the formula for the volume of a right cylinder, $V=(\pi) r^{2} h$, where $V$ is the measured neck volume and $h$ is the measured neck length. This computed radius was multiplied by 2 to obtain the "calculated" and "effective" diameters in Figure 10, A and B.

$S E R$ and varicosity volumes were calculated in the same way that was described for the dendritic spine volume.

The total number of vesicles in the presynaptic axonal varicosity was computed by counting every vesicle with a membrane and clear center in each section of the varicosity. Since synaptic vesicles are about $0.07-$ $0.08 \mu \mathrm{m}$ in diameter, a vesicle defined by a clear center should appear in only one section.

\section{Selection of sample fields for comparing PSD areas on reconstructed dendritic spines with PSD areas on other spines in the cerebellar molecular layer}

The goal of this test was to determine whether the dimensions measured from the reconstructed spines might be extended to a larger population of spines on Purkinje spiny branchlets. We needed a relatively simple and accurate method to sample other spines in the molecular layer. We discovered in our initial analysis that there exists a positive correlation between PSD area on individual dendritic spines and several other spine features. PSDs are easy to recognize and trace through serial sections, and therefore PSD area was chosen as an index of comparison among reconstructed spines and a larger population of spines in sample fields selected from other portions of the cerebellar molecular layer.

Four sample fields were photographed from the same sections as were used for series 20 and 25 to control for possible differences in section thickness that might alter dimensions if they were obtained from other sections. One sample for each series was obtained from a $200 \mu \mathrm{m}^{2}$ area surrounding the reconstructed dendrite (adjacent sample), and a second sample was obtained from a $200 \mu \mathrm{m}^{2}$ area located 40 (series 20) or 200 (series 25) linear microns away from the adjacent sample (distant sample). Both fields for series 20 were located approximately 60 linear $\mu \mathrm{m}$ from the Purkinje cells and for series 25, 150 linear $\mu \mathrm{m}$ from the Purkinje cells. Every spine PSD with a portion located on the central "sample" section was measured through adjacent serial sections on photomicrographs at a digitizing bitpad in the IGL. Since 8 serial sections completely contained the largest spine synapse we have reconstructed, these 4 sample fields were photographed through 20 serial sections to completely contain every PSD with an edge on the central sample section.

To calibrate the bitpad measuring system with measures obtained on the movie reconstruction system, 14 synapses were traced and measured through serial sections on both systems. The synaptic areas measured from photomicrographs on the bitpad were $19 \%$ smaller than the traces obtained from the movie reconstruction system. It is easier to follow, identify, and measure PSDs on the movie system, and therefore the discrepancy between these 2 systems is likely to result from missing parts of synapses on the photomicrographs. Therefore, the PSD areas obtained by the bitpad measurements were increased by $19 \%$ before comparing PSD areas in the sample fields with those on the reconstructed spines. From these 4 sample fields, an additional 152 spine PSD areas were measured and compared with those from spines reconstructed with the movie system.

\section{Section thickness determination}

Initially, section thickness was assumed to be 0.06 or $0.07 \mu \mathrm{m}$, based on the interference color of the sections floating on water in the boat of the diamond knife (Meek, 1976). The Purkinje cell dendrites are approximately cylindrical, so an independent estimate of section thickness could be obtained by measuring the diameters of longitudinally sectioned dendrites at their maxima in single sections and comparing this measured diameter to the number of sections that the dendrite appeared in (see Fig. 5 of Harris and Stevens, 1988). Section thickness was then calculated as

$$
\begin{aligned}
& \text { Thickness }(\mu \mathrm{m} / \text { section })= \text { measured diameter }(\mu \mathrm{m}) / \\
& \text { number of sections. }
\end{aligned}
$$

For series 20 , the average section thickness from 5 measures was calculated to be $0.06 \mu \mathrm{m}$, and for series 25 , the average section thickness from 5 measures was calculated to be $0.07 \mu \mathrm{m}$, in close agreement with the estimates obtained by interference coloration of the sections.

\section{Biophysical modeling}

To test whether cerebellar spine necks are cylindrical, empirical measures of neck lateral surface areas were compared with values that would be predicted for a right cylinder. To compute the predicted neck surface area, the neck radius was first calculated from the measured neck volume (V), where $V=(\pi) r^{2} h$ and $h$ is the measured neck length. Then this calculated value of the neck radius was substituted into the formula for the lateral surface area $(\mathrm{SA})$ of a cylinder, where predicted $\mathrm{SA}=2(\pi) r h$. Average spine neck diameters along this length of cylinder were then computed by multiplying the calculated $r$ value by 2 , and this value compared favorably with measured neck diameters.

To test whether cerebellar spine heads are spherical, measured and predicted spine head surface areas were compared. To compute the predicted head surface area, the radius of each head was first calculated from the measured head volume $(V)$, where $V=4 / 3(\pi) r^{3}$ for a sphere. Then the calculated $r$ was used to determine the predicted surface area, where $\mathrm{SA}=4(\pi) r^{2}$ for a sphere. This comparison was used because it was impossible to measure reliably the diameter, and not a chord, of the head. Figure 7 of Wilson (1984) was used to construct the "percent reduction" curves of Figures $10, A, B$ (see Results for further description of the methods used). 

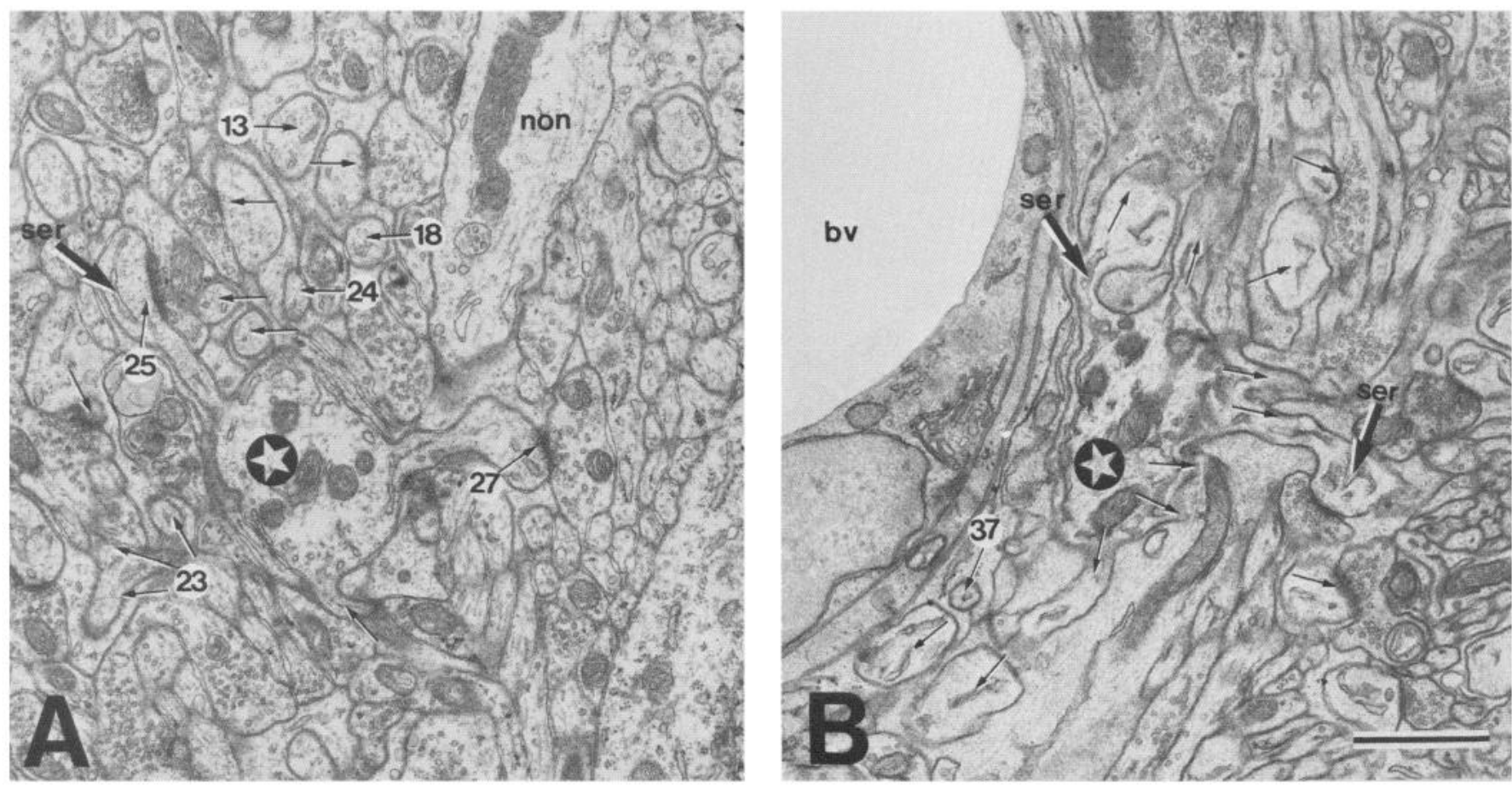

Figure 1. A, Purkinje spiny branchlet (star) of series 20 located in the middle of the dense neuropil of the molecular layer. This is section number 23 of the series. Arrows indicate all spine parts on this section that were found to be connected to this dendritic segment through serial reconstruction. Portions of some spines illustrated in subsequent figures in complete reconstructions are located here and numbered. Number 23 indicates portions of a branched spine. A nonspiny dendrite (non) shared axonal varicosities with some of the spines connected to this spiny branchlet. Smooth endoplasmic reticulum (ser) is identified in one spine (large arrow). Same magnification as in $B$. B, Purkinje spiny branchlet (star) of series 25 located near a blood vessel $(b v)$. This is section number 27 of the series. Cisternae of smooth endoplasmic reticulum (ser, large arrows) are easily seen in the spines. Arrows indicate all spine parts found to be connected to this dendrite in previous or subsequent sections, and the neck of spine number 37 is cross-sectioned. Scale bar, $1 \mu \mathrm{m}$.

\section{Statistical analyses}

The RS1 statistical package (Bolt, Beranek and Newman, Cambridge, MA) was used to obtain correlations and comparisons described in the Results. For comparisons of mean values, the sample distributions were first tested for normality by the Wilkes-Shapiro test, and then the $F$ test for homogeneity of variance was applied. If these criteria were met, then a parametric $t$ test was used to test differences between mean values. The nonparametric Mann-Whitney $U$ statistic was used for the comparisons if both distributions were not normal and their variance was not homogeneous.

\section{Results}

Three-dimensional reconstructions of dendritic segments from Purkinje spiny branchlets

One spiny dendritic segment was located approximately $50 \mu \mathrm{m}$ from the Purkinje cell bodies in the molecular layer (series 20, Fig. 1A). It was completely surrounded by the parallel axons of the granule cells. The second dendritic segment was located approximately $150 \mu \mathrm{m}$ from the Purkinje cells and was selected for its location near a blood vessel because it would be one of the first dendrites reached by the diffusing fixative and therefore should be optimally preserved (series 25 , Fig. $1 B$ ). The region between the blood vessel and one side of this dendrite had very few granule cell axons.

Asymmetric synapses on dendritic spines of Purkinje spiny branchlets are characterized by a thick postsynaptic density (PSD), a widened cleft with dense staining material, and a presynaptic axonal varicosity filled with round clear vesicles. Nonspiny dendrites of stellate or basket cells (labeled "non" in Fig. 1A) form similar asymmetric synapses with some of the same axonal varicosities. Each spine has cisternae of SER (Figs. 1, $A$, $B ; 2)$.

Front and back views of three-dimensional (3-D) reconstructions from these 2 dendritic segments illustrate the high density of dendritic spines on Purkinje spiny branchlets (Fig. 2, $A, B$ ). All of the dendritic spines were graphically removed and triangles left at their origins to illustrate the position about the circumference of the dendritic segments. The dendritic segment of series 20 was $2.6 \mu \mathrm{m}$ long and had 43 spine origins for a density of 14.3 spines $/ \mu \mathrm{m}$; spines emerged from all sides of the dendrite, though in somewhat irregular patches. The dendritic segment of series 25 was $4.6 \mu \mathrm{m}$ long and had 54 spine origins for a density of 11.6 spines $/ \mu \mathrm{m}$. Spines emerged preferentially from the side of series 25 facing towards the neuropil, while the side of this dendrite facing the blood vessel had only 2 spine origins (arrow along blood vessel, bv).

Three-dimensional reconstructions of all spines completely contained within these serial sections were graphically edited into their head and neck compartments. Three spines illustrated in Figure $3 A$ show the trend that spines with longer necks tend to have smaller heads than spines with shorter necks $(r=-0.41$, $p<0.0005)$. A similar editing of the SER into head and neck portions shows how its shape mimics the overall spine shape (Fig. 3B).

Dimensions of spines, synapses, and axonal varicosities are combined for series 20 and 25, and are summarized in Table 1. Spines from series 25 had on average $70 \%$ larger PSD areas $(p<0.001), 20 \%$ larger head volumes $(p<0.005), 59 \%$ more SER in the heads $(p<0.001)$, and $41 \%$ more vesicles in the 
Series 20

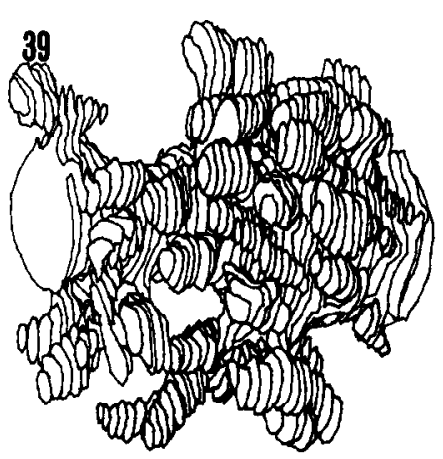

Series 25
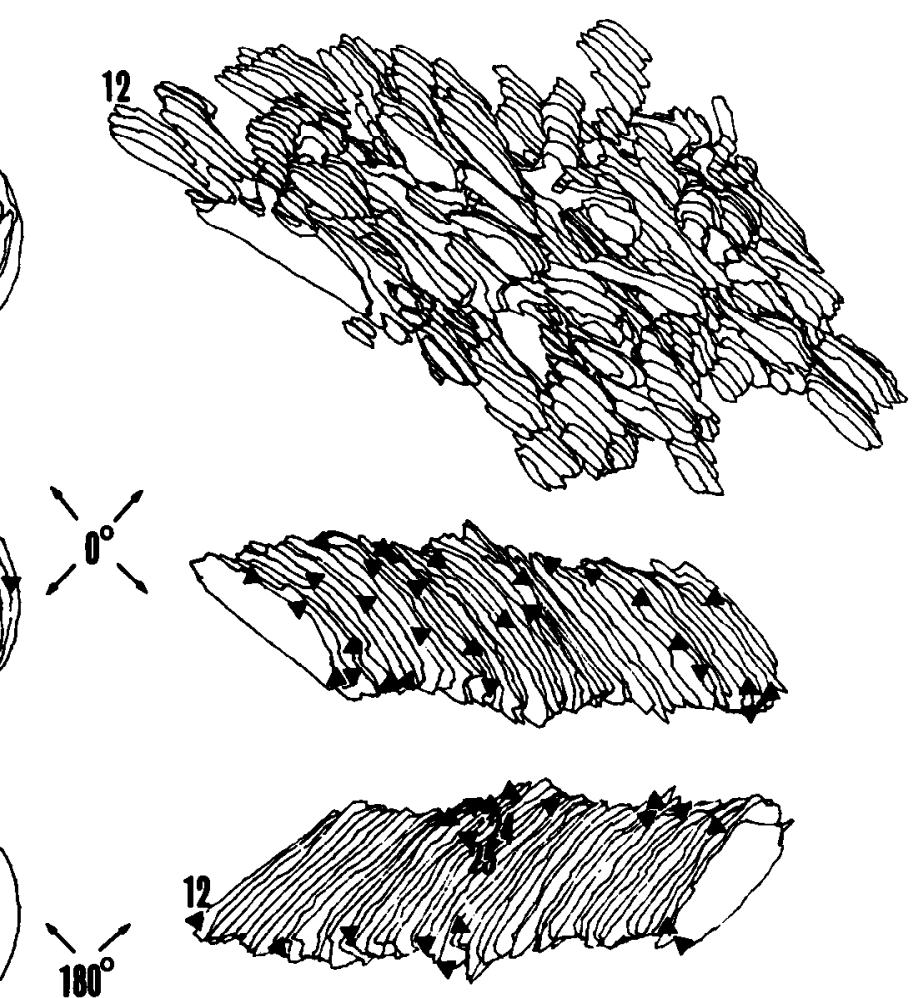
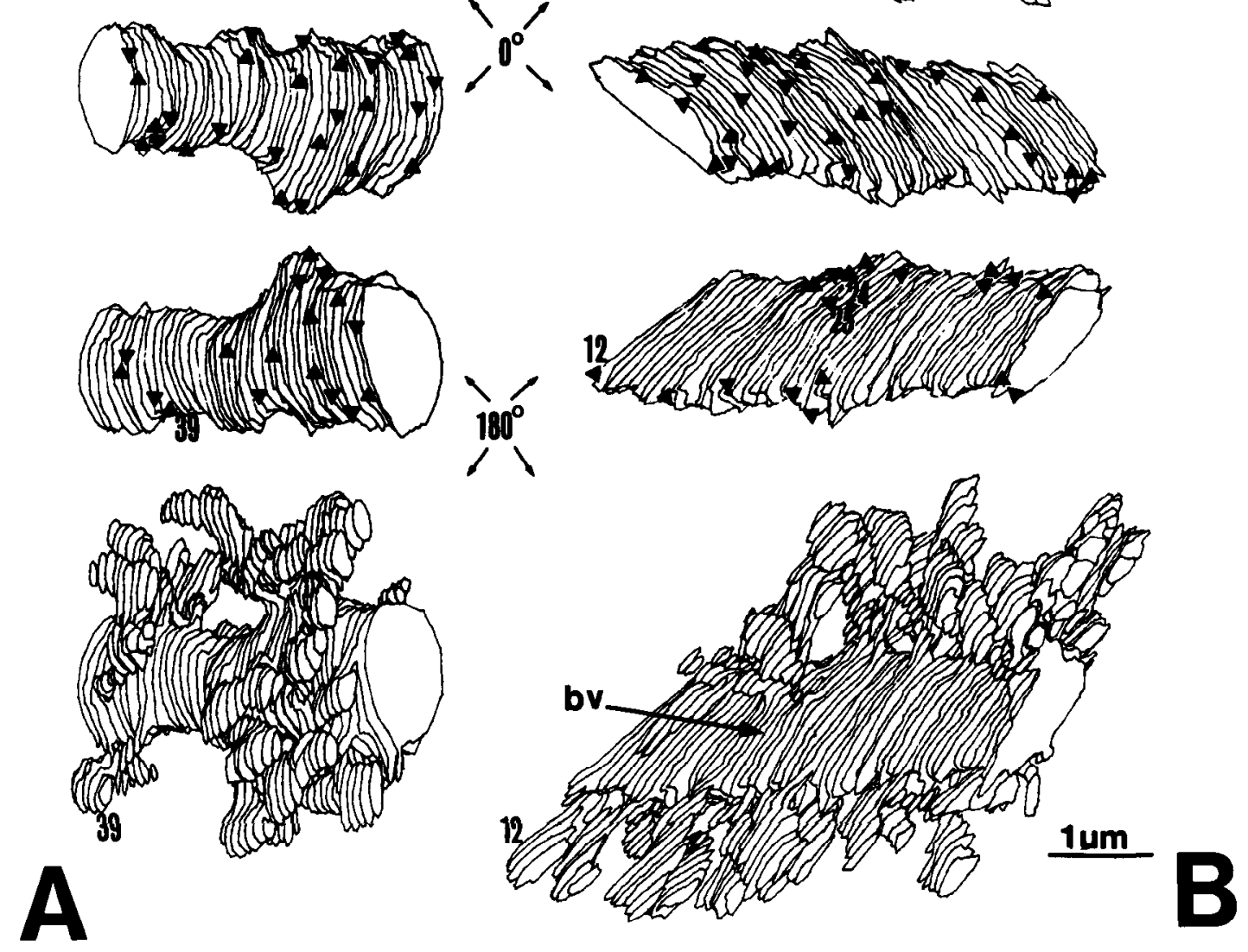

Figure 2. $A$ and $B$. Complete reconstructions of dendritic segments from series 20 and 25 , each rotated $180^{\circ}$ about their central axis. In the middle pair of reconstructions, spines were graphically removed from the dendrite so that density and distribution could be visualized with triangles positioned at spine origins. Spine 39 of series 20 and spine 12 of series 25 are labeled for position reference across the reconstructions. Spines 24 and 25 of series 25 were the only spine origins facing the blood vessel $(b v)$ and their synapses shared one of the only 2 axons coursing between the blood vessel and this segment of dendrite. The diameter of the dendritic segment in series 20 averaged $1.27 \pm 0.18 \mu \mathrm{m}$ along its length, and the series 25 segment diameter averaged $1.04 \pm 0.20 \mu \mathrm{m}$ along its length.

presynaptic axonal varicosities $(p<0.05)$ than spines of series 20 . The neck volume, SER volume in the neck, neck diameters, and neck lengths were not significantly different between series 20 and 25. Complete reconstruction of dendritic spines and their presynaptic axonal varicosities was possible for 64 of the 97 spines originating from these 2 dendritic segments. The SER tracings were incomplete for 3 of the spines. Eleven of the axonal varicosities were shared by more than 1 spine for a total of 53 (see below for discussion of varicosity sharing). The correlation $(r)$ between each spine or axonal dimension and the PSD area on the spine was determined, and the probability of a significant difference $(p<0.05)$ from zero correlation was tested (Horowitz,
1974). For both series, the PSD area was positively correlated with the total spine volume (Fig. 4), the SER volume, and the number of vesicles in the presynaptic axonal varicosity (Table 1). The PSD area was not significantly correlated with any dimension of the spine neck, though longer spines tended to have smaller PSDs (Table 1).

The PSD areas of these 64 reconstructed dendritic spines were not significantly different from the PSD areas of 152 other spines in the 2 adjacent and 2 distant sample fields (see Materials and Methods above for selection of sample fields). Since PSD area is well correlated with some other spine dimensions, this finding suggests that the range of spine dimensions and features ob- 

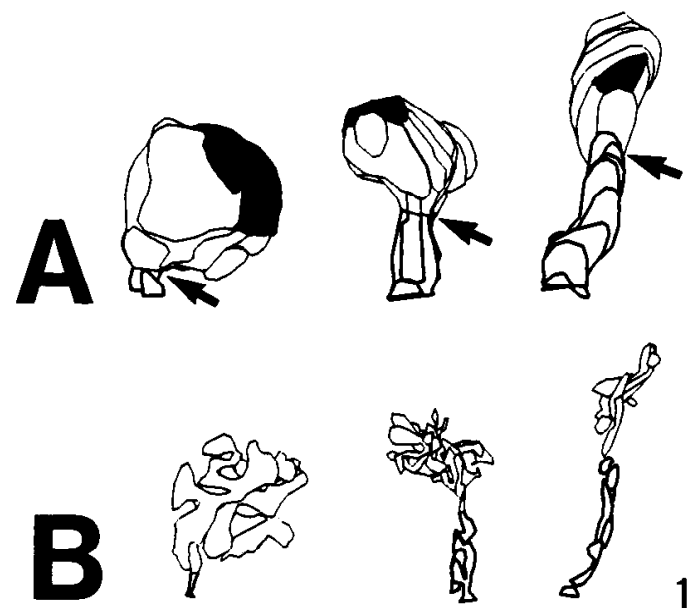

1 um

Figure 3. $A$, Dendritic spines, and $B$, the SER within them, graphically edited into head (thin lines) and neck (thick lines) compartments, where arrows indicate the head/neck junction. Spines with shorter necks tended to have larger heads and PSDs (filled black areas) than spines with longer necks, as illustrated from left to right of this figure. The shape of the SER mimics overall spine shape. The volumes of the spine and SER compartments were computed from these edited reconstructions. Scale bar is for both $A$ and $B$.

tained from these reconstructed dendritic segments is not likely to be unique among Purkinje cells but overlaps the larger population.

\section{SER of dendritic spines}

SER is the only organelle consistently found in dendritic spines. Complete serial reconstructions of this organelle consistently revealed it to be connected to the SER of the parent dendrite (see figs. 19 and 20 of Harris and Stevens, 1988). The shape of a dendritic spine mimics the overall shape of its contained SER (Fig. 3B). A tight relationship between spine and SER shape could be studied quantitatively in spines that were sectioned

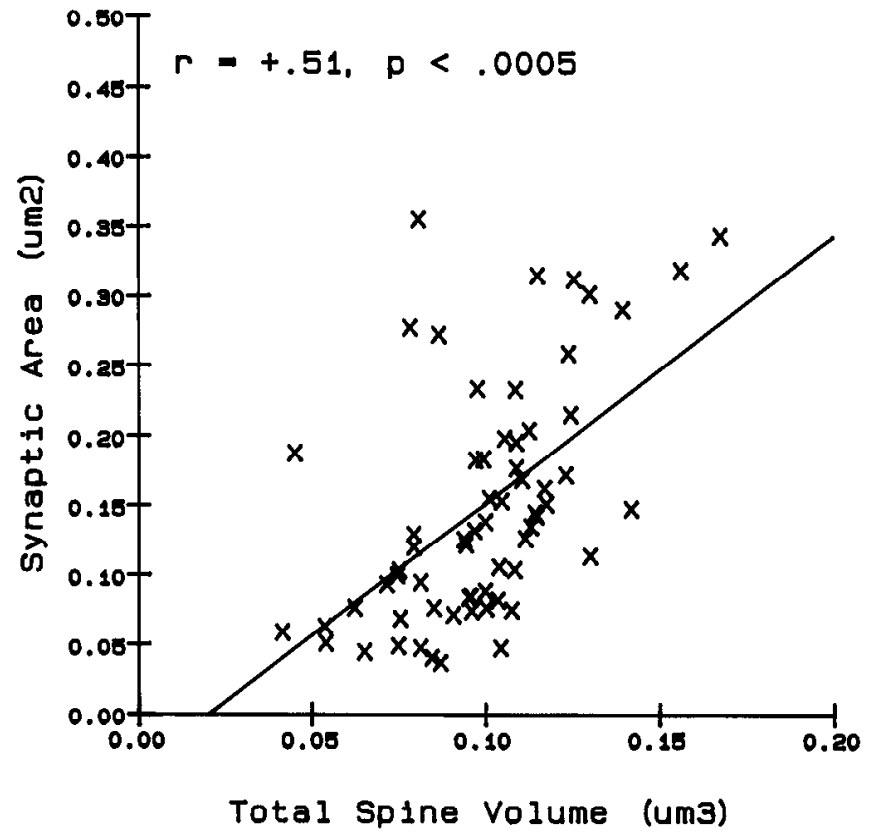

Figure 4. Relationship between total spine volume and PSD area on the spine head. A best-fit line is superimposed on the data points for individual spines.

perpendicularly to their long axis, i.e., cross-sectioned. In these 2 series, 12 spines were cross-sectioned and the cross-sectional areas of the spine, SER, and synapse were compared along the length of the spine, beginning with the spine neck origin at the parent dendrite. Graphs for a short spine neck (Fig. 5A), an average spinc ncck (Fig. $5 B$ ), and a long spinc neck (Fig. $5 C$ ) show a good correlation between spine area and SER area. The correlation between spine cross-sectional area and SER crosssectional area along the length of these spines averaged +0.78 for the cross-sectioned spines, with 11 spines between +0.60

\begin{tabular}{|c|c|c|c|c|c|c|}
\hline \multirow[b]{2}{*}{ Feature } & \multirow[b]{2}{*}{$N$} & \multirow[b]{2}{*}{ Mean \pm SD } & \multicolumn{2}{|l|}{ Range } & \multirow[b]{2}{*}{$r$} & \multirow[b]{2}{*}{$p$} \\
\hline & & & Low & High & & \\
\hline Synaptic PSD area $\left(\mu \mathrm{m}^{2}\right)$ & 64 & $0.15 \pm 0.08$ & 0.04 & 0.36 & - & - \\
\hline Spine volume $\left(\mu \mathrm{m}^{3}\right)$ & 64 & $0.12 \pm 0.02$ & 0.06 & 0.18 & +0.51 & $<0.0005$ \\
\hline Head & 64 & $0.10 \pm 0.02$ & 0.04 & 0.17 & +0.55 & $<0.0005$ \\
\hline Neck & 64 & $0.02 \pm 0.01$ & 0.002 & 0.095 & +0.16 & ns \\
\hline Spine surface area $\left(\mu \mathrm{m}^{2}\right)$ & 64 & $1.12 \pm 0.18$ & 0.69 & 1.63 & +0.15 & ns \\
\hline Head & 64 & $0.90 \pm 0.17$ & 0.47 & 1.27 & +0.30 & $<0.01$ \\
\hline Neck & 64 & $0.28 \pm 0.15$ & 0.05 & 1.16 & -0.16 & ns \\
\hline SER volume $\left(\mu \mathrm{m}^{3}\right)$ & 61 & $0.02 \pm 0.01$ & 0.008 & 0.04 & +0.41 & $<0.005$ \\
\hline Head & 62 & $0.017 \pm 0.008$ & 0.002 & 0.038 & +0.42 & $<0.0005$ \\
\hline Neck & 62 & $0.003 \pm 0.002$ & 0.0002 & 0.014 & -0.13 & ns \\
\hline Axonal varicosity $\left(\mu \mathrm{m}^{3}\right)$ & 53 & $0.25 \pm 0.12$ & 0.04 & 0.60 & +0.17 & $\mathrm{~ns}$ \\
\hline Vesicle number & 53 & $485 \pm 246$ & 38 & 1234 & +0.42 & $<0.005$ \\
\hline Spine length $(\mu \mathrm{m})$ & 64 & $1.22 \pm 0.30$ & 0.72 & 2.61 & -0.20 & ns \\
\hline Head & 64 & $0.57 \pm 0.05$ & 0.43 & 0.68 & +0.51 & $<0.0005$ \\
\hline Neck & 64 & $0.66 \pm 0.32$ & 0.12 & 2.18 & -0.27 & $<0.05$ \\
\hline Neck diameter $(\mu \mathrm{m})$ & 64 & $0.20 \pm 0.04$ & 0.09 & 0.31 & +0.13 & ns \\
\hline
\end{tabular}




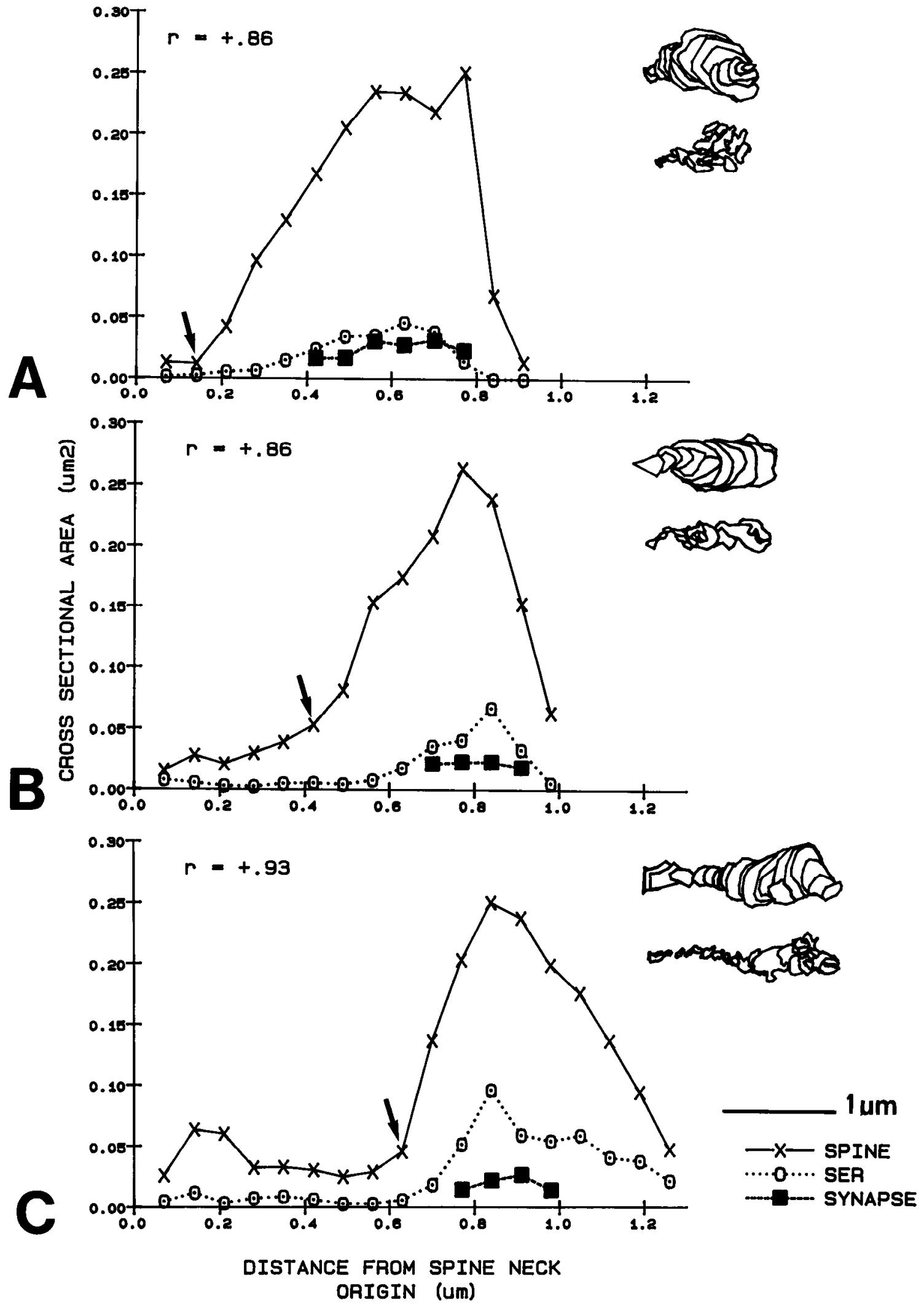

Figure 5. A-C, Comparison of cross-sectional areas of 3 spines, their SER, and synapses, with length along the spine beginning at the spine neck origin with the parent dendrite. The correlation between spine and SER cross-sectional areas for each spine is listed in the upper-left corner. Arrows on the graphs indicate the head/neck junction. $B$ is spine 37 of series 25 whose neck is illustrated in Figure $1 B$. Insets, Three-dimensional reconstructions of each spine (upper reconstruction of each figure) and its SER (lower reconstruction of each figure), rotated approximately $45^{\circ}-$ $60^{\circ}$ from cross section, with hidden lines removed. See text for discussion. 


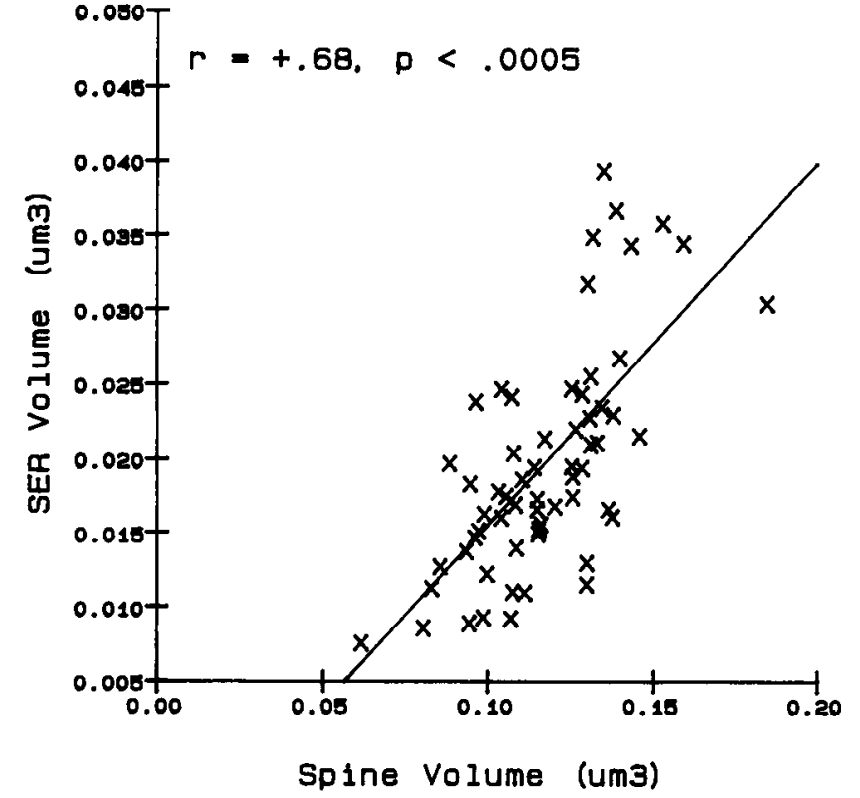

Figure 6. Relationship between total spine volume and the total volume of SER in the spines. A best-fit line, computed by the RS1 program, is superimposed on the data points for individual spines.

and +0.93 and the 12 th spine at +0.23 . The 12 th spine had no head and was therefore simply a long thin projection with a small synapse and irregular fluctuations in the spine and SER areas along its length. The area of the SER in the spine head is

\begin{tabular}{|c|c|c|c|}
\hline Feature & $\begin{array}{l}\text { Nonsharing } \\
\text { varicosities } \\
(n=34)\end{array}$ & $\begin{array}{l}\text { Sharing } \\
\text { varicosities } \\
(n=21) \\
\end{array}$ & $p$ \\
\hline PSD area $\left(\mu \mathrm{m}^{2}\right)$ & $0.17 \pm 0.09$ & $0.10 \pm 0.05$ & $<0.001$ \\
\hline Spine volume $\left(\mu \mathrm{m}^{3}\right)$ & $0.12 \pm 0.02$ & $0.11 \pm 0.02$ & $=0.05$ \\
\hline Head & $0.11 \pm 0.02$ & $0.09 \pm 0.02$ & $<0.02$ \\
\hline Neck & $0.02 \pm 0.01$ & $0.02 \pm 0.02$ & ns \\
\hline SER volume $\left(\mu \mathrm{m}^{3}\right)$ & $0.022 \pm 0.008$ & $0.016 \pm 0.005$ & $<0.001$ \\
\hline Head & $0.019 \pm 0.008$ & $0.013 \pm 0.005$ & $<0.001$ \\
\hline Neck & $0.003 \pm 0.002$ & $0.003 \pm 0.003$ & ns \\
\hline Varicosity volume ${ }^{a}\left(\mu \mathrm{m}^{3}\right)$ & $0.24 \pm 0.12$ & $0.31 \pm 0.13$ & ns \\
\hline Vesicle number & $472 \pm 244$ & $553 \pm 282$ & ns \\
\hline Spine length $(\mu \mathrm{m})$ & $1.15 \pm 0.25$ & $1.35 \pm 0.41$ & ns \\
\hline Head & $0.58 \pm 0.05$ & $0.55 \pm 0.05$ & $<0.02$ \\
\hline Neck & $0.58 \pm 0.26$ & $0.79 \pm 0.42$ & $<0.05$ \\
\hline Neck diameter $(\mu \mathrm{m})$ & $0.19 \pm 0.04$ & $0.17 \pm 0.04$ & ns \\
\hline
\end{tabular}

Means \pm SD are given. Abbreviations: $n$, number of complete spines that also had complete varicosities; $p$, probability that the means of the features are equal for sharing and nonsharing varicosities; ns, means are not significantly different for nonsharing and sharing varicosities.

${ }^{a}$ Thirteen different varicosities were shared by more than one synapse.

maximal in sections containing the synapse, and the average correlation between synaptic cross-sectional area and SER crosssectional area for these 12 spines was +0.60 .

The SER occupied between 8 and $26 \%$ of the total spine neck
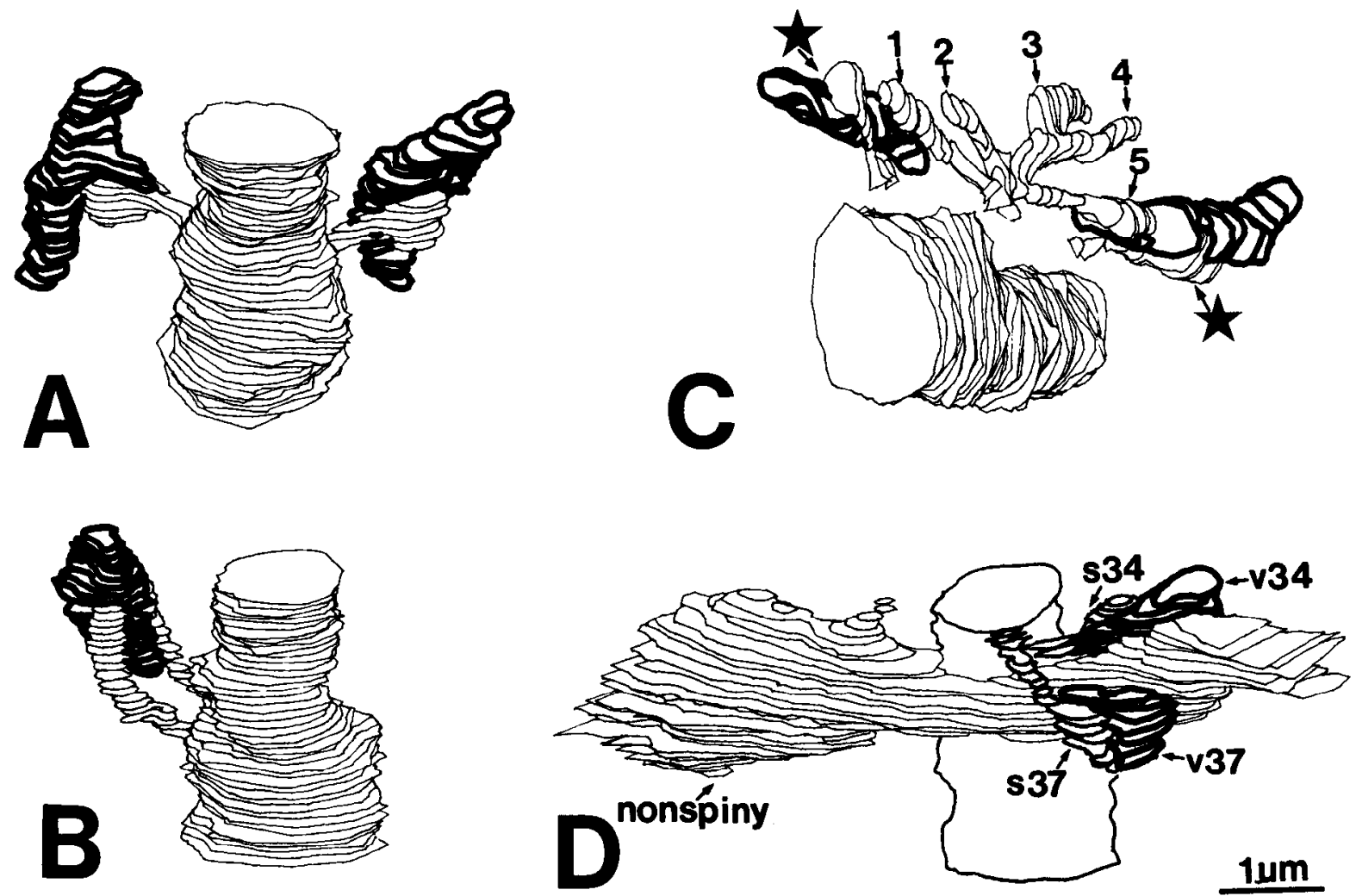

Figure 7. A, Spines 27 and 25 of series 20 (thin lines), not sharing their presynaptic axonal varicosities (thick lines). All other spines on this dendritic segment were graphically removed for clarity. $B$. Sharing of a presynaptic axonal varicosity by 2 dendritic spines of the same dendritic segment. $C$, Sharing of 2 different presynaptic axonal varicosities by synapses located on heads 1 and 5 of branched spine (\#23 in Fig. $1 A$ ), with synapses located on the heads of 2 distant unbranched spines (stars) from the same dendritic segment. $D$, Sharing of axonal varicosities ( $v 34$, v37) by dendritic spines $(s 34, s 37)$ and shaft synapses of a nonspiny dendrite (non in Fig. $1 A$ ). Scale bar for $A-D$. 


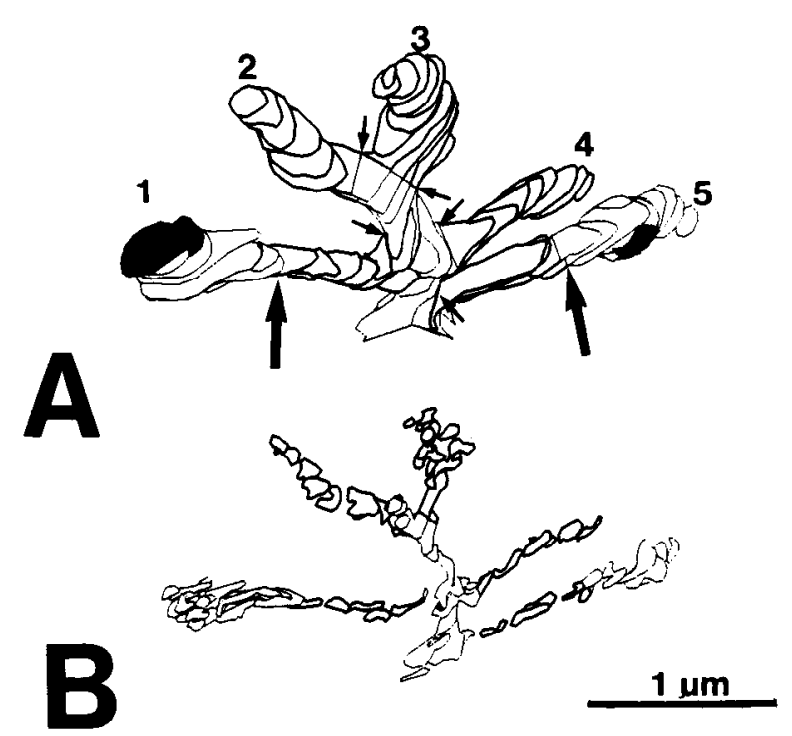

Figure 8. $A$, Branched spine 23, and $B$, the SER within it. Small arrows of $A$ indicate the junction between the protrusion (thin lines up the center) and each spine branch; large arrows indicate the junction between the neck (thick lines) and the head (thin lines) of branches 1 and 5 where PSDs are filled to indicate the location of synapses on these branches.

cytoplasm, and between 5 and $30 \%$ of the total spine head cytoplasm. Total spine volume and total SER volume was well correlated for the complete population of 64 reconstructed spines, where larger spines had more SER than smaller spines (Fig. 6).

\section{Axonal varicosities presynaptic to dendritic spines}

Each dendritic spine was found to have only 1 synapse on its head, and usually the presynaptic axonal varicosities of the parallel fibers that formed the spine synapse had only one synapse on them. A relationship of one spine to one axonal varicosity is illustrated by spines 25 and 27 of series 20 in Figure $1 A$, and is graphically reconstructed in Figure $7 A$. Total spine volume, head volume, and PSD areas were proportional to the total number of vesicles in the presynaptic axonal varicosity $(r=$ $+0.43,+0.37,+0.41$, respectively; $p<0.005)$. Spine neck volume was not significantly correlated with vesicle number $(r=$ $+0.06)$.

\section{Sharing of presynaptic axonal varicosities}

Some of the axonal varicosities formed more than 1 synapse and shared a contiguous population of vesicles among 2 or more synapses. Of 63 complete axonal varicosities in these 2 series, $17(27 \%)$ were shared by more than one synapse. Most $(19 \%)$ of the sharing occurred between neighboring spines of the same dendritic segment (Fig. 7, $B, C$ ). Occasionally (6\%), axonal varicositics were shared by spine synapses of Purkinje branchlets and shaft synapses of nonspiny dendrites in the same field (Fig. $7 D$ ). Rarely ( $2 \%$ ), axonal varicosities were shared by spines of different dendrites (not shown).

Dimensions of spines and synapses associated with nonsharing axonal varicosities were compared with those associated with sharing axonal varicosities (Table 2). Synaptic area, spine head volume, and the volume of SER in the head were all greater for spines with nonsharing axonal varicosities. Nonsharing and sharing axonal varicosities did not differ significantly in the number of vesicles they contained; therefore, fewer vesicles might be available for each synapse located on a sharing varicosity.
Table 3. Comparison of spine branches with and without synapses

\begin{tabular}{llcl} 
& $\begin{array}{l}\text { With } \\
\text { synapses } \\
(n=5)\end{array}$ & $\begin{array}{l}\text { Without } \\
\text { synapses } \\
(n=6)\end{array}$ & $p$ \\
\hline Beature & $0.11 \pm 0.05$ & $0.05 \pm 0.02$ & $<0.01$ \\
SER volume $\left(\mu \mathrm{m}^{3}\right)$ & $0.02 \pm 0.007$ & $0.006 \pm 0.001$ & $<0.02$ \\
Total length $(\mu \mathrm{m})$ & $1.24 \pm 0.22$ & $1.04 \pm 0.34$ & $\mathrm{~ns}$ \\
Neck diameter $(\mu \mathrm{m})$ & $0.22 \pm 0.06$ & $0.23 \pm 0.03$ & $\mathrm{~ns}$ \\
\hline
\end{tabular}

Means \pm SD are given. Abbreviations: $n$, number of spine branches; $p$, probability that these means are equal.

Spines associated with nonsharing axonal varicosities had shorter necks than spines associated with sharing axonal varicosities, though the total spine length and neck diameters did not differ significantly between these 2 groups of spines.

\section{Evidence for spine remodeling: branched spines and spines without PSDs}

Dendritic spines were referred to as "branched spines" if: more than 1 spine emerged from a single protrusion of the dendrite, and this protrusion had dimensions in the range of single spine necks; it contained SER; and it did not contain microtubules, and was therefore not a small dendritic branch. The series 20 dendritic segment had 2 branched spines. One had 5 branches2 with synapses on their heads (\#1 and 5) and $3(\# 2,3,4)$ having no PSDs or axonal varicosities, but ending bluntly in astrocytic sheaths (Fig. 8A). Both branches of the second branched spine in series 20 had no PSDs and ended in astrocytic sheaths. The series 25 dendritic segment also had 2 branched spines. One had 2 branches, both with synapses-one sharing its presynaptic varicosity with an unbranched spine of the same dendritic segment and the other having a nonsharing synapse on one branch and no synapse on the second branch. Together these findings suggest that 1 in 16 (4 of 64) cerebellar dendritic spines might be branched.

The head and neck compartments of branched spines were compared with single spines by graphical editing of each branch and its SER from the common base that protruded from the dendrite (Fig. 8, $A, B$ ). Branches with synapses did not differ significantly from unbranched spines for any spine or axonal varicosity dimension. However, branches with synapses wcrc larger and contained more SER than branches without synapses, though neck diameter and total length did not differ significantly (Table 3).

Of the 64 complete spines in these 2 series only one unbranched spine had no PSD, though it was apposed to a vesiclefilled axonal varicosity, and its total volume $\left(0.08 \mu \mathrm{m}^{3}\right)$, neck length $(0.55 \mu \mathrm{m})$, and neck diameter $(0.19 \mu \mathrm{m})$ were within the range of other unbranched spines.

\section{Implications of spine dimensions for the resistance hypothesis}

Biophysical models that simulate the transfer of synaptic current from spine heads through their necks to the recipient dendrites assume the spine heads to be spherical and the spine necks to be cylindrical. The measured head surface areas of these cerebellar spines deviated from predictions based on spherical assumptions by $-9 \pm 10 \%$ (Fig. $9 A$ ). The measured neck surface areas of these reconstructed spines deviated from predictions hased on cylindrical assumptions by $-25 \pm 9 \%$ (Fig. $9 B$ ). We assumed these deviations from spherical and cylindrical predictions to result from experimental measurement error because 

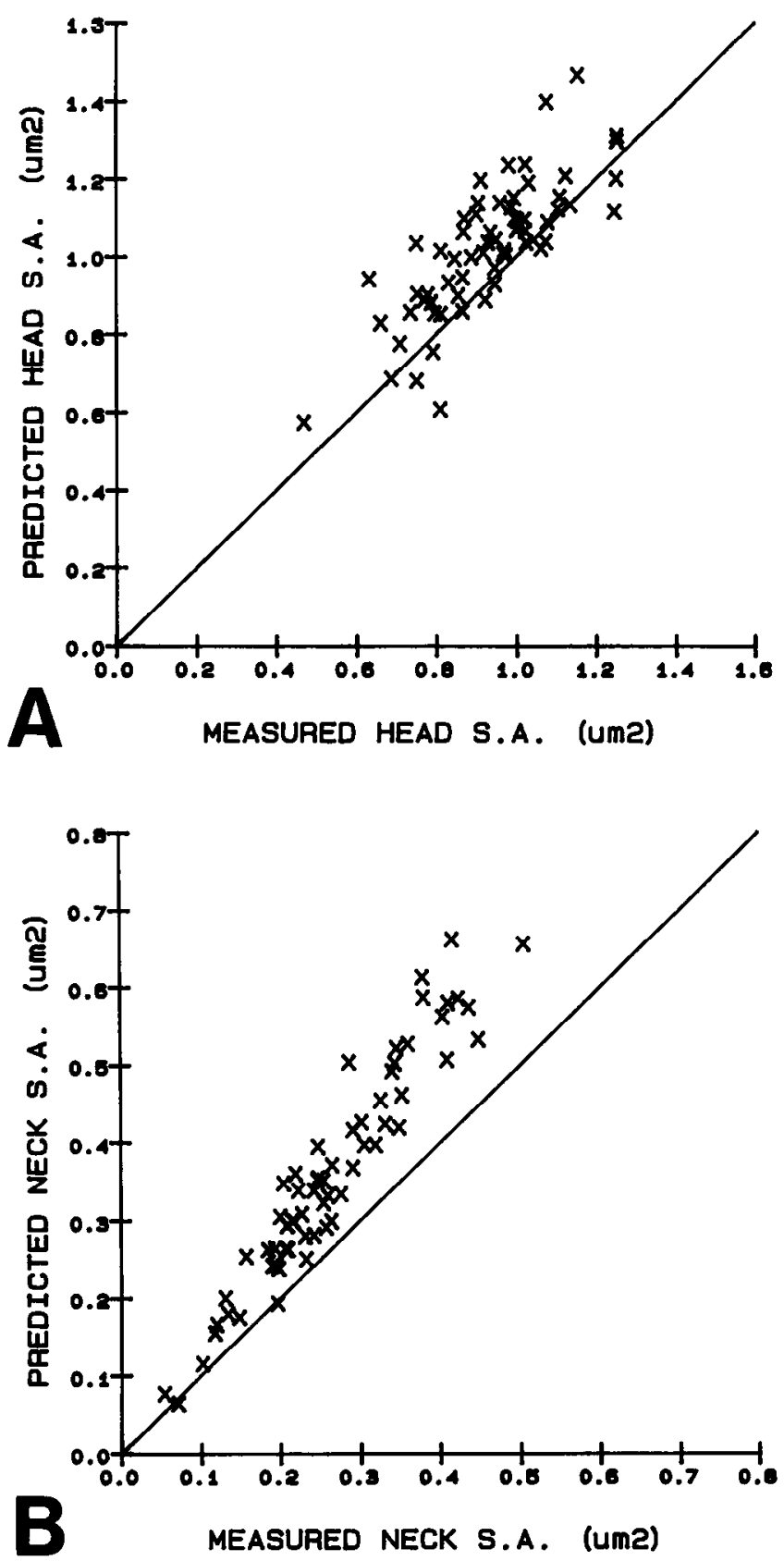

Figure 9. A, Deviation of measured head surface area (S.A.) from spherical predictions is $-9 \pm 10 \%$. The line indicates where empirical and predicted values match. If these spine heads were "oval" shapes or had very uneven contours, the data points would fall to the right of the line, where more surface area would be measured than predicted for a sphere. Since most of the points fall to the left, we assume we have missed some of the surface area associated with these heads (see text). $B$, Deviation of measured neck surface area $(S . A$.$) from the cylindrical$ predictions is $-25 \pm 9 \%$. The line illustrates where empirical and predicted values match. If these necks had uneven contours or more surface area/volume than would be predicted for a cylinder, the points should fall to the right of the line.

there is too little measured surface area for the measured volume. Boundary surface areas are the most difficult structures to recognize on the electron micrographs, especially for the small spine necks, and therefore portions might have been missed.

We used results generated in figure $7 \mathrm{a}$ of Wilson (1984) to test whether the dimensions of these Purkinje spine necks might
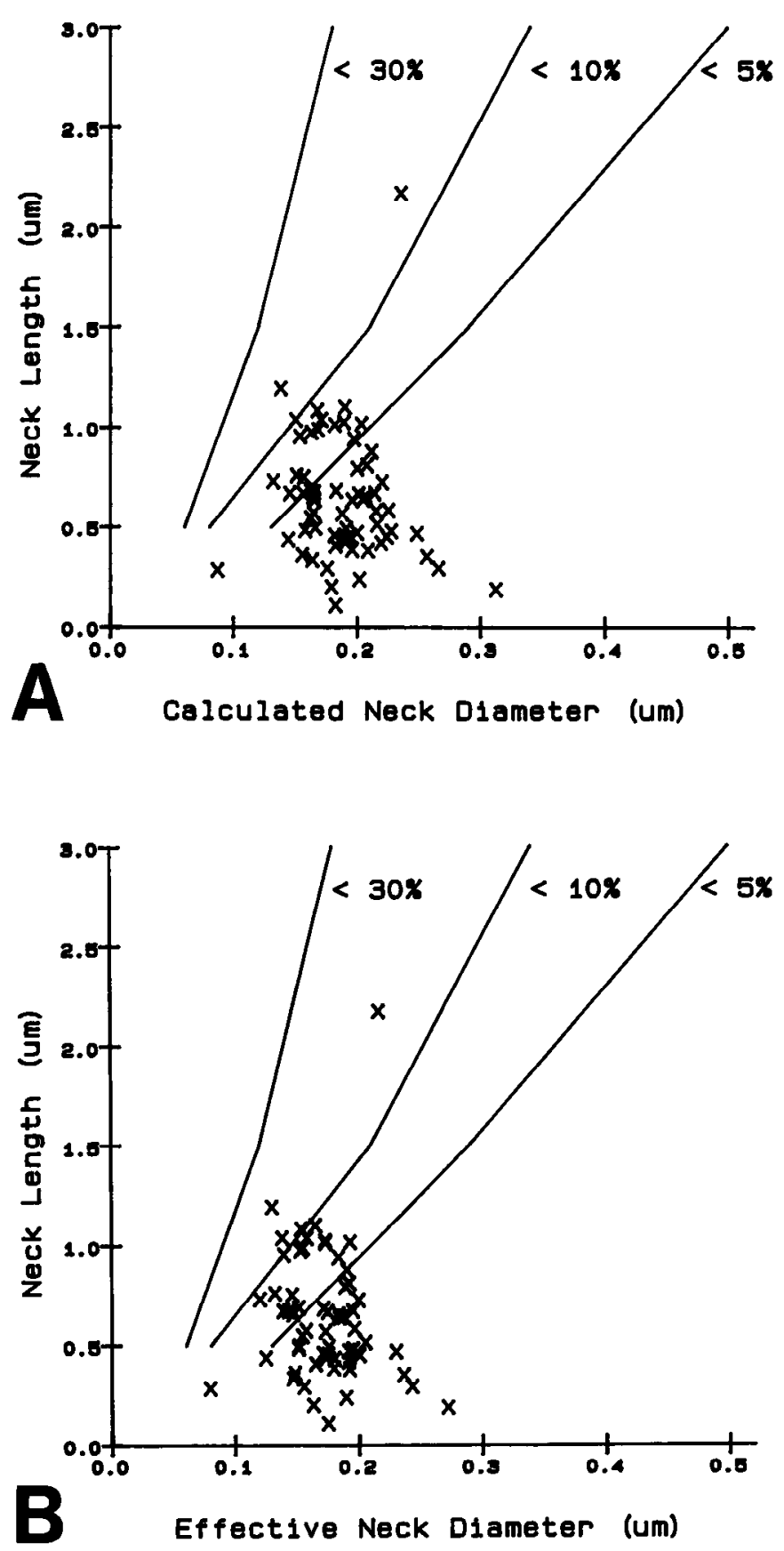

Figure 10. A, Theoretical percent reduction from maximal transfer of synaptic charge that would occur if the synapse occurred on the dendritic shaft. The spine neck dimensions, assuming that SER has the same resistivity as the spine neck cytoplasm, are superimposed on the theoretical curves. Forty-five spines reduce charge transferred by less than $5 \%, 17$ spines are between 5 and $10 \%$, and 2 spines are above $10 \%$ (see text for further explanation). $B$. Theoretical percent reduction in maximal charge transfer due to spine neck dimensions if the SER membrane is highly resistive. The effective neck diameter was recomputed by subtracting the SER volume from the total neck volume. Forty-four spines reduce charge transfer by less than $5 \%, 16$ spines are between 5 and $10 \%$, and 4 spines are between 10 and $30 \%$ reduction.

reduce the amount of synaptic charge reaching the recipient dendrite from the theoretical maximum that would be possible if the synapse had instead occurred directly on the dendritic shaft. The Wilson model used the alpha function (alpha $=50$ ) to simulate a transient synaptic conductance change that reached 
a peak value of $5 \mathrm{nS}$ on a spherical spine head. (For a detailed discussion of the alpha function, see Wilson, 1984, and Brown et al., 1988.) Spine membrane resistance of $2000 \Omega-\mathrm{cm}^{2}$ and cytoplasmic resistance of $100 \Omega-\mathrm{cm}$ were used to calculate peak transfer of synaptic charge for spines varying in diameters from 0.1 to $0.5 \mu \mathrm{m}$ and lengths of $0.5,1.5$, and $3.0 \mu \mathrm{m}$. To generate our theoretical percent reduction curves (Fig. $10, A, B$ ), the intersection of neck diameters and lengths that would cause 5 , 10 , and $30 \%$ reduction of peak current, relative to the asymptotic maximums for shaft synapses, were computed from figure $7 \mathrm{a}$ of Wilson (1984). Our measured spine neck dimensions were then superimposed on these theoretical curves.

If the SER occupying the spine neck were assumed to have the same resistance as the spine neck cytoplasm, then most of these spine necks would cause less than $5 \%$ reduction in transfer of synaptic charge (Fig. 10A). In the worst case, the resistance of the SER membrane would completely block current flow through the SER, and the volume that the SER cisternae occupy in the spine cytoplasm would be unavailable for charge transfer. To test the effect of highly resistant SER membrane, the volume of SER found in the spine necks was subtracted from the total neck volume and the diameter of the necks recalculated for the remaining volume using the cylindrical formula. This calculation revealed a slight increase in the number of spines that would reduce charge transfer (by 10-30\%). Even in this extreme case for SER resistance, most of the spines would still cause less than $5 \%$ reduction in charge transfer (Fig. 10B).

\section{Discussion}

These results show that dendritic spines of Purkinje spiny branchlets occur at a higher density along the dendrite than has been previously reported (e.g., Palay and Chan-Palay, 1974; Pysh and Weiss, 1979; see also Harris and Stevens, 1988, for discussion of differences in spine densities). Spine size is proportional to the volume of SER they contain, to PSD area on their heads, and to the number of vesicles in the presynaptic axonal varicosity. Spines with larger heads and synapses tend to have shorter necks than spines with smaller heads and synapses. Spines that do not share their presynaptic axonal varicosities tend to have larger heads and synapses than spines that share their axonal varicosities. Some spines are branched and approximately half of the branches have no PSDs or axonal varicosities associated with them. The spine heads are essentially spherical, and spine necks tend to be cylindrical, and therefore these spines are good candidates for modeling the effects that variations in their dimensions might have on the transfer of charge from the synapse to the recipient dendrite.

\section{Spine sample selection}

The detailed description of spines from 2 dendritic segments located in the cerebellar cortex of 2 different rats seemingly represents a description of a very small sample of the extensive population of dendritic spines located there. Both rats were sexually mature adults but were of different weights and were subjected to different fixation protocols. The segment of series 20 was specifically selected for its location in the middle of dense neuropil, where it was surrounded by the parallel fiber axons. The dendritic segment of series 25 was specifically selected for its location near a blood vessel, possibly enhancing the quality of fixation. Both series showed excellent quality of fixation as judged by continuous plasmalemmas, unswollen mitochondria, well-preserved and continuous SER, and well-preserved and continuous microtubules in the dendrites. Differences in spine dimensions between these 2 dendritic segments are not likely to have occurred from nonspecific swelling because the difference was not uniform along the spine; neck dimensions were the same for both series, though heads were on average larger for series 25 . Similarly, differences in section thickness estimates for the 2 series does not account for the variation in spine dimensions. It seems possible that the older age of the series 25 rat and/or the more distal location of this dendritic segment might have contributed to the relatively larger spine head dimensions, though an age-related or field-position effect will require further parametric testing.

Selection of 2 dendritic segments photographed through serial sections provided an unbiased sampling of spines, because at the time when the dendrites were chosen for photography on the middle sections of these series, we could not know any of the spinc propertics that would occur in preceding or subscquent sections. The areas of PSDs on the reconstructed spines overlapped a much larger population of PSDs on spines located in other fields of the molecular layer, supporting the assertion that the reconstructed spines are not unique among Purkinje spiny branchlets, but probably represent a larger population of spines found there.

Complete reconstructions of dendritic segments gave new information about local circuitry. These are the first demonstrations that spines located along a single Purkinje spiny branchlet often share the same population of presynaptic vesicles, which presumably contain excitatory amino acid(s) neurotransmitters (Stone, 1979; Schulman, 1983). The presence of branched spines, some lacking PSDs, on these untreated, adult dendrites suggests they are normal features of the neuropil and might represent ongoing plasticity or growth and differentiation of spines in adults (cf. Sotelo, 1973, 1975a, b; Herndon and Oster-Granite, 1975; Hirano and Dembitzer, 1975; Privat, 1975; Chen and Hillman, 1982a, b, 1985; Hirano, 1983). It is unlikely, however, that the cerebellar branched spines represent the splitting of single synapses and division of a single spine because the heads of a single-branched spine are widely separated in the neuropil and do not share the same presynaptic axonal varicosity (NeitoSampedro et al., 1982).

\section{Relationships between spine geometry and anatomical indicators of synaptic efficacy}

We have obsesrved that larger spine heads are associated with more SER, larger synapses, and more vesicles in the presynaptic axonal varicosity. As synapses are larger and the presynaptic varicosity has more vesicles, synaptic transmission is presumed to be more effective. We propose that growth of the spine head parallels growth of the PSD and associated SER in response to enhanced synaptic efficacy. A greater synaptic efficacy could result in more rapid influx of ions and possibly a higher concentration of ions in the spine head near to the synapse (Gamble and Koch, 1987). Electron microscopic microanalysis and oxalate precipitation have shown that SER contains calcium, and it has been proposed that this organelle might act as a final site to buffer the spine cytoplasm from high concentrations of calcium (Gray and Guillery, 1963; Westrum et al., 1980; Burgoyne et al., 1983; Fifkova et al., 1983; Andrews and Reese, 1986; Andrews et al., 1987). Alternatively, calcium might be released from the SER to cooperate with ion influx during synaptic transmission and facilitate activation of proteins, such as actin or calcium-dependent calmodulin, in the spine (Henkart, 1980; 
Crick, 1982; Gray, 1982; Fifkova and Delay, 1982; Katsumaru et al., 1982; Matus et al., 1982; Landis and Reese, 1983; Markham and Fifkova, 1986; Brown et al., 1988, for further review). Either of these possible functions might involve the growth or swelling of SER in the spine head in response to enhanced synaptic efficacy.

Differences in spine neck diameters do not parallel differences in spine head volume, head SER volume, PSD area, or the number of vesicles in the axonal varicosity. Neck diameters are the same for spines with large or small heads, with large or small PSD areas, and with axons containing many or few vesicles. Neck diameters are the same for spines with nonsharing or sharing axonal varicosities. Neck diameters do not differ on branches of branched spines with or without PSDs, though the absence of PSDs is associated with less total branch volume and less SER. These observations suggest that spine neck diameter is not strongly influenced by activity level at the synapse on the spine head.

Involvement of organelles in spine creation and shape control

Research over the last 2 decades has shown that an internal "cytoskeleton," consisting of neurofilaments (NF), microtubules (MT), and a subcellular matrix is in some way responsible for control of neurite shape (for review, see Stevens et al., 1988). Through a combination of experimental methods and computer-assisted serial electron microscopy, this cytoskeleton concept has been further elaborated (Ellias and Stevens, 1980; Sasaki et al., 1983; Sasaki-Sherrington et al., 1984; Jacobs and Stevens, $1986 \mathrm{a}, \mathrm{b})$. These studies conclude that, in addition to the microtubules and neurofilaments, organelles such as mitochondria and SER may control the assembly of cytoskeletal elements, as well as contribute to the control of neurite shape.

Sasaki-Sherrington et al. (1984) first noticed that organelles always had an additional cytoplasmic volume associated with them. This extra cytoplasmic volume was present in direct proportion to the volume of the organelle itself and was called an "obligatory volume." The relationship was initially noticed in retinal AII amacrine cells and has since been extended to several other cell types (see Stevens et al., 1988, for review). These cells have neurites with large prominent varicosities. When reconstructed at the EM level, it became clear that, without exception, each varicosity contained a mitochondrion and, conversely, each mitochondrion was associated with a varicosity. In addition, there was a good relationship between organelle volume and the total synaptic surface area found on the varicosity.

The good correlation between dendritic spine volumes and their associated SER volumes is surprisingly similar to the result reported for dendritic varicosities (Sasaki-Sherrington et al., 1984). Our data also show a very good correlation between the spine SER volumes and synaptic area on the spines. Thus, it may be that dendritic spines are specialized organelle-containing compartments suited to support synapses, like dendritic varicosities.

\section{Influence of spine neck geometry on resistance to synaptic transmission}

In the more than 30 years since Chang (1952) first proposed that changes in spine neck dimensions could modulate synaptic efficacy, many biophysical models have supported similar views (Diamond et al., 1970; Rall, 1970, 1974, 1978; Perkel, 1982/ 83; Koch and Poggio, 1983; Kawato et al., 1984; Turner, 1984; Wilson, 1984; Perkel and Perkel, 1985). For mathematical purposes, these models have assumed the spine head to be spherical and the spine neck to be cylindrical. Our empirical measures support these geometrical assumptions for dendritic spines of the Purkinje spiny branchlets.

The plasma membrane resistance and cytoplasmic resistance have been assumed to fall in the range measured from cell somas and dendrites because direct measurement of intrinsic spine characteristics has been impossible. Measurement of synaptic conductance changes that occur at individual spine synapses has also been impossible, though biophysical modeling shows that the range of effect that spine dimensions have on total charge transferred to the dendrite is nonlinearly related to the magnitude of conductance changes that occur at the synapses (e.g., Koch and Poggio, 1983; Wilson, 1984; Rall and Segev, 1988). Therefore, our application of the Wilson model to these Purkinje spines must be considered a preliminary strategy to test whether the dimensions of a population of spines are likely to influence transfer of charge to the recipient dendrite. If the values of synaptic conductance $\left(5 \times 10^{-9} \mathrm{~S}\right)$, time to peak conductance $(1 /$ alpha, alpha $=50)$, specific membrane resistance $\left(2000 \Omega-\mathrm{m}^{2}\right)$, and cytoplasmic resistivity $(100 \Omega-\mathrm{cm})$ used in the Wilson model are within the range that normally occurs at Purkinje dendritic spines, then we could conclude from our measurements that the spine neck dimensions are unlikely to reduce transfer of synaptic charge by more than $20 \%$ even if the SER membrane is highly resistant. Further analysis will be required if the intrinsic characteristics of these spines or the size of synaptic conductance changes that occur at their synapses are grossly different from those used in the Wilson model.

If these theoretical predictions are correct, lengthening or thinning of the spines with parallel fiber activation could produce as much as $80 \%$ reduction in synaptic transmission, whereas shortening and widening of most of these necks would result in less than $10 \%$ enhancement of synaptic transmission. Therefore, these cerebellar spine necks are positioned on the theoretical curves where participation in the reduction of synaptic efficacy could occur by thinning or lengthening of the spine necks, but no change in neck geometry would significantly enhance transfer of charge to the recipient dendrite.

Repeated and conjunctive stimulation of climbing fiber and parallel fiber inputs to Purkinje cells results in a decrement of postsynaptic response to the parallel fiber input (Ito et al., 1982; Ito, 1984, 1985), and behavioral habituation of the nictitating membrane response (Thompson, 1986). If alterations in cerebellar spine geometry are associated with these reductions in synaptic efficacy or behavioral response, then stimulated Purkinje spines should be longer and thinner (i.e., more resistive) than unstimulated spines (Ito et al., 1982; Ito, 1984, 1985). In contrast, during hibernation, a time when activation of Purkinje cells is likely to be low, the dendritic spines appear to have swollen heads on short necks in Golgi preparations of the ground squirrel cerebellum (Boycott, 1982). Paradoxically, deafferentation or noninnervation of Purkinje spiny branchlets results in long, thin, and frequently branched spines, often with PSDs, but no presynaptic axons (Sotelo, 1973, 1975a, b; Herndon and Oster-Granite, 1975; Hirano and Dembitzer, 1975; Landis and Reese, 1977; Chen and Hillman, 1982a, b, 1985; Taveres et al., 1983). Surely these noninnervated spines are not being highly activated by axonal input to cause elongation. Perhaps cerebellar spines continue to elongate and branch until they establish an effective synapse with a presynaptic partner. Then an activitydependent regulation of spine shape and size, SER volume, and PSD area might ensue.

This pattern of response decrement that occurs at Purkinje 
cells contrasts with hippocampal cclls, where repcatcd stimulation of their axonal input results in long-term potentiation (LTP) of the physiological response. Results from anatomical studies of single thin sections from stimulated hippocampus have been interpreted to suggest that spine necks swell and shorten, heads become rounder or conversely, more concave, and PSD area increases (Van Harreveld and Fifkova, 1975; Moshkov et al., 1977, 1980; Fifkova and Anderson, 1981; Lee et al., 1981; Desmond and Levy, 1983, 1986a, b, 1988; Chang and Greenough, 1984; Wenzel et al., 1985; Petukhov and Popov, 1986) Other hippocampal studies suggest that short and stubby spines can mediate LTP and that spine neck shortening and widening is not necessary for LTP (Reeves and Steward, 1986; Harris et al., 1987, 1988). If spine neck constriction serves to restrain biochemical products of LTP to activated synapses, then spine geometry could act to confer specificity of LTP to the locus of LTP induction (Brown et al., 1988).

Complete 3-dimensional reconstructions of dendritic spines and biophysical modeling should help to resolve whether spine geometry changes sufficiently, and in the appropriate directions, to be involved in depression of cerebellar response or enhancement of hippocampal response following repeated activation of synaptic inputs. Specific modeling of diffusion through dendritic spines will be required to determine whether spines with the dimensions reported here are likely to restrain various proteins and/or ions to the heads of selectively activated spines (Shepherd, 1979; Gamble and Koch, 1987; Brown et al., 1988). If compartmentation is an important function of spine necks, then we would expect that changes in synaptic efficacy would not alter the diameter of existing constricted spine necks, but rather influence the dimensions of the spine head and SER volume, the features we have seen here to fluctuate across adult cerebellar spines of differing morphologies.

\section{References}

Andrews, S. B., and T. S. Reese (1986) Intracellular structure and elemental analysis in rapid-frozen neurons. Ann. NY Acad. Sci. 483: 284-294.

Andrews, S. B., R. D. Leapman, D. M. D. Landis, and T. S. Reese (1987) Distribution of calcium and potassium in presynaptic nerveterminals from cerebellar cortex. Proc. Natl. Acad. Sci. USA 84: 1713-1717.

Benshalom, G., and E. L. White (1988) Dendritic spines are susceptible to structural alterations by degeneration of their presynaptic afferents. Brain Res. 443: 377-382.

Boycott, B. (1982) Some further comments concerning dendritic spines. Trends Neurosci. 5: 328-329.

Brown, T. H, V. C. Chang, A. H. Ganong, C. L. Keenan, and S. R. Kelso (1988) Biophysical properties of dendrites and spines that may control the induction and expression of long-term synaptic potentiation. Neurol. Neurobiol. 35: 201-264.

Burgoyne, R. D., E. G. Gray, and J. Barron (1983) Cytochemical localization of calcium in the dendritic spine apparatus of the cerebral cortex and at synaptic sites in the cerebellar cortex. J. Anat. (Lond.) 136: 634-635.

Carnavale, N. T., and D. Johnston (1982) Electrophysiological characterization of remote chemical synapses. J. Neurophysiol. 47: 606621 .

Chang, H. T. (1952) Cortical neurons with particular reference to the apical dendrites. Cold Spring Harbor Symp. Quant. Biol. 17: 189202.

Chang, F. L. F., and W. T. Greenough (1984) Transient and enduring morphological correlates of synaptic activity and efficacy in the rat hippocampal slice. Brain Res. 309: 35-46.

Chen, S., and D. E. Hillman (1982a) Plasticity of the parallel fiberPurkinje cell synapse by spine takeover and new synapse formation in the adult rat. Brain Res. 240: 205-220.
Chen, S., and D. E. Hillman (1982b) Plasticity of cerebellar parallel fibers following developmental deficits in synaptic number. Brain Res. 333: 369-373.

Cher, S., and D. E. Hillman (1985) Marked reorganization of Purkinje cell dendrites and spines in adult rat following vacating of synapse due to deafferentation. Brain Res. 245: 131-135.

Connor, J. R., M. C. Diamond, and R. E. Johnson (1980) Aging and environmental influences on two types of dendritic spines in the rat occipital cortex. Exp. Neurol. 70: 371-379.

Coss, R. G., and D. H. Perkel (1985) The function of dendritic spinesA review of theoretical issues. Behav. Neurol. 44: 151-185.

Coss, R. G., J. G. Brandon, and A. Globus (1980) Changes in morphology of dendritic spines on honeybee calycal interneurons associated with cumulative nursing and foraging experience. Brain Res. 192: 49-59.

Crick, F. (1982) Do dendritic spines twitch? Trends Neurosci. 5: 4446.

Desmond, N. L., and W. B. Levy (1983) Synaptic correlates of associative potentiation/depression: An ultrastructural study in the hippocampus. Brain Res. 265: 21-30.

Desmond, N. L., and W. B. Levy (1986a) Changes in the numerical density of synaptic contacts with long-term potentiation in the hippocampal dentate gyrus. J. Comp. Neurol. 253: 466-475.

Desmond, N. L., and W. B. Levy (1986b) Changes in the postsynaptic density with long-term potentiation in the dentate gyrus. J. Comp. Neurol. 253: 476-482.

Desmond, N. L., and W. B. Levy (1988) Anatomy of associative longterm synaptic modification. Neurol. Neurobiol. 35: 265-307.

Diamond, J., E. G. Gray, and G. M. Yasargil (1970) The function of dendritic spines: An hypothesis. In Excitatory Synaptic Mechanisms, Proceedings of the 5th International Meeting of Neurobiologists, P. Andersen and J. Jensen, eds., pp. 213-222, Universitets Forlaget, Oslo.

Ellias, S., and J. K. Stevens (1980) The dendritic varicosity: A mechanism for electrically isolating the dendrites of cat amacrine cells. Brain Res. 196: 365-372.

Feldman, M., and A. Peters (1979) A technique for estimating total spine numbers on Golgi-impregnated dendrites. J. Comp. Neurol. 188: $527-542$.

Fifkova, E., and C. L. Anderson (1981) Stimulation-induced changes in dimensions of stalks of dendritic spines in the dentate molecular layer. Exp. Neurol. 74: 621-627.

Fifkova, E., and R. J. Delay (1982) Cytoplasmic actin in dendritic spines as a possible mediator of synaptic plasticity. J. Cell Biol. 95: 350-365.

Fifkova, E., J. A. Markham, and R. J. Delay (1983) Calcium in the spine apparatus of dendritic spines in the dentate molecular layer. Brain Res. 266: 163-168.

Freire, M. (1978) Effects of dark rearing on dendritic spines in layer IV of the mouse visual cortex. A quantitative electron microscopical study. J. Anat. 126: 193-201.

Gamble, E., and C. Koch (1987) The dynamics of free calcium in dendritic spines in response to repetitive synaptic input. Science 236 : 1311-1315.

Globus, A., M. R. Rosensweig, E. L. Bennett, and M. C. Diamond (1973) Effects of differential experience on dendritic spine counts in rat cerebral cortex. J. Comp. Physiol. Psychol. 82: 175-181.

Gray, E. G. (1959) Axo-somatic and axo-dendritic synapses of the cerebral cortex: An electron microscope study. J. Anat. 93: 420-433.

Gray, E. G. (1982) Rehabilitating the dendritic spine. Trends Neurosci. 5: 5-6.

Gray, E. G., and R. W. Guillery (1963) A note on the dendritic spine apparatus. J. Anat. 997: 389-392.

Harris, K. M., and D. M. D. Landis (1986) Synaptic membrane structure in area CA1 of the rat hippocampus. Neuroscience 19:857-872.

Harris, K. M., and J. K. Stevens (1986) Smooth endoplasmic reticulum in dendritic spines. Soc. Neurosci. Abstr. 11: 88.17.

Harris, K. M., and J. K. Stevens (1988) Study of dendritic spines by serial electron microscopy and three-dimensional reconstructions. Neurol. Neurobiol. 37: 179-199.

Harris, K. M., J. Trogadis, and J. K. Stevens (1985) Three dimensional structure of dendritic spines in the rat hippocampus (CA1) and cerebellum. Soc. Neurosci. Abstr. 10: 306.

Harris, K. M., F. E. Jensen, and B. Tsao (1987) Development of hippocampal LTP, synapses, and spines. Soc. Neurosci. Abstr. 13: 1429(394.12).

Harris, K. M., F. E. Jensen, and B. Tsao (1988) Ultrastructure, de- 
velopment, and plasticity of dendritic spine synapses in area CAl of the rat hippocampus: Extending our vision with serial electron microscopy and three dimensional analyses. Neurol. Neurobiol. (in press).

Henkart, M. (1980) Identification and function of intracellular calcium stores in axons and cell bodies of neurons. Fed. Proc. 39: 2783-2789.

Herndon, R. M., and M. L. Oster-Granite (1975) Effect of granule cell destruction on development and maintenance of Purkinje cell dendrite. Adv. Neurol. 12: 361-371.

Hirano, A. (1983) The normal and aberrant development of synaptic structures between parallel fibers and Purkinje cell dendritic spines. J. Neural. Transm. Suppl. 18: 1-18.

Hirano, A., and H. M. Dembitzer (1975) Aberrant development of the Purkinje cell dendritic spine. Adv. Neurol. 12: 353-360.

Horowitz, L. M. (1974) Elements of Statistics for Psychology and Education, McGraw-Hill, New York.

Horwitz, B. (1984) Electrophoretic migration due to postsynaptic potential gradients: Theory and application to autonomic ganglion neurons and to dendritic spines. Neuroscience $12: 887-905$.

Ito, M. (1984) The modifiable neuronal network of the cerebellum. Jpn. J. Physiol. 34: 781-792.

Ito, M. (1985) Cerebellar plasticity as the basis of motor learning. In Recent Achievements in Restorative Neurology: I. Upper Motor Neuron Functions and Dysfunctions, J. C. Eccles and N. R. Dimitrijevic, eds., pp. 222-237, Karger, New York.

Ito, M., M. Sakurai, and P. Tongroach (1982) Climbing fibre induced depression of both mossy fibre responsiveness and glutamate sensitivity of cerebellar Purkinje cells. J. Physiol. (Lond.) 324: 113-134.

Jack, J. J. B., D. Noble, and R. W. Tsien (1975) Electric Current Flow in Excitable Cells, Oxford U. P., London.

Jacobs, J. R., and J. K. Stevens (1986a) Experimental modification of PC12 neurite shape with the microtubule-depolymerizing drug Nocodazole. J. Cell Biol. 103: 907-915.

Jacobs, J. R., and J. K. Stevens (1986b) Changes in the organization of the neuritic cytoskeleton during nerve growth factor activated differentiation of PC12 cells: A serial electron microscopic study of the development and control of neurite shape. J. Cell Biol. 103: 895-906.

Johnston, D., and T. Brown (1983) Interpretation of voltage-clamp measurements in hippocampal neurons. J. Neurophysiol. 50: 464 486.

Jones, E. G., and T. P. S. Powell (1969) Morphological variations in the dendritic spines of the neocortex. J. Cell Sci. 5: 509-529.

Katsumaru, H., F. Murakami, and N. Tsukahara (1982) Actin filaments in dendritic spines of red nucleus neurons demonstrated by immunoferritin localization and heavy meromyosin binding. Biomed. Res. 3: 337-340.

Kawato, M., T. Hamaguchi, F. Murakami, and N. Tsukahara (1984) Quantitative analysis of electrical properties of dendritic spines. Biol. Cybernet. 50: 447-454.

Koch, C., and T. Poggio (1983) A theoretical analysis of electrical properties of spines. Proc. R. Soc. London [Biol.] 218: 455-477.

Landis, D. M. D., and T. S. Reese (1977) Structure of the Purkinje ccll membrane in staggerer and weaver mutant mice. J. Comp. Neurol. 171: 247-260.

Landis, D. M. D., and T. S. Reese (1983) Cytoplasmic organization in cerebellar dendritic spines. J. Cell Biol. 97: 1169-1178.

Lee, K. S., F. Schottler, M. Oliver, and G. Lynch (1980) Brief bursts of high-frequency stimulation produce two types of structural change in the rat hippocampus. J. Neurophysiol. 44: 247-258.

Markham, J. A., and E. Fifkova (1986) Actin filament organization within dendrites and dendritic spines during development. Dev. Brain Res. 27: 263-269.

Matus, A., M. Ackermann, G. Pehling, H. R. Byers, and K. Fujiwara (1982) High actin concentrations in brain dendritic spines and postsynaptic densities. Proc. Natl. Acad. Sci. USA 79: 7590-7594.

Meek, G. A. (1976) Practical Electron Microscopy for Biologists, Wiley, New York.

Miller, J. P., W. Rall, and J. Rinzel (1985) Synaptic amplification by active membrane in dendritic spines. Brain Res. 325: 325-330.

Moshkov, D. A., L. L. Petrovskaia, and A. G. Bragin (1977) Posttetanic changes in the ultrastructure of the giant spinous synapses in hippocampal field CA3. Dokl. Akad. Nauk. USSR 237: 1525-1528.

Moshkov, D. A., L. L. Petrovskaia, and A. G. Bragin (1980) Ultrastructural study of the bases of postsynaptic potentiation in hippocampal sections by the freeze-substitution method. Tsitologiia 22 : $20-26$.

Neito-Sampedro, M., S. F. Hoff, and C. W. Cotman (1982) Perforated postsynaptic densities: Probable intermediates in synapse turnover. Proc. Natl. Acad. Sci. USA 79: 5718-5722.

Palay, S. L., and V. Chan-Palay (1974) Cerebellar Cortex: Cytology and Organization, Springer-Verlag, New York.

Pearlstein, R. A., L. Kirschner, J. Simons, S. Machell, W. F. White, and R. L. Sidman (1986) A multimodal system for reconstruction and quantification of ncurologic structures. Anal. Quant. Cytol. Ilistol. 8: 108-115.

Perkel, D. H. (1982-1983) Functional role of dendritic spines. Physiologie (Paris) 78: 695-699.

Perkel, D. H., and D. J. Perkel (1985) Dendritic spines: Role of active membrane in modulating synaptic efficacy. Brain Res. 325: 331-335.

Peters, A., and I. R. Kaiserman-Abramhof (1970) The small pyramidal neuron of the rat cerebral cortex. The perikaryon, dendrites and spines. Am. J. Anat. 127: 321-356.

Petukhov, V. V., and V. I. Popov (1986) Quantitative-analysis of ultrastructural-changes in synapses of the rat hippocampal field CA3 in vitro in different functional-states. Neuroscience 18: 823-835.

Privat, A. (1975) Dendritic growth in vitro. Adv. Neurol. 12: 201216.

Pysh, J. J., and G. M. Weiss (1979) Exercise during development induces an increase in Purkinje cell denditic tree size. Science 206: 230-231.

Rall, W. (1970) Cable properties of dendrites and effects of synaptic location. In Excitatory Synaptic Mechanisms. Proceedings of the 5th International Meeting of Neurobiologists, pp. 175-187, Universitets Forlaget, Oslo.

Rall, W. (1974) Dendritic spines, synaptic potency and neuronal plasticity. In Cellular Mechanisms Subserving Changes in Neuronal Activity, C. Woody, K. Brown, T. Crow, and J. Knispel, eds., Brain Information Service, UCLA, Los Angeles.

Rall, W. (1978) Dendritic spines and synaptic potency. In Studies in Neurophysiology, A. K. McIntyre and K. Porter, eds., Cambridge U. P., Cambridge.

Rall, W., and I. Segev (1988) Synaptic integration and cxcitable dendritic spine clusters: Structure/function. Neurol. Neurobiol. 37: 263282.

Ramón y Cajal, S. (1891) Sur la structure de l'ecorce cerebrale de quelques mammiferes. Cellule 7: 124-176.

Ramón y Cajal, S. (1911) Histologie du Systeme Nerveux de l'Homme et Vertebres, Instituto Ramon y Cajal, Madrid [2nd printing (1972)].

Rausch, G., and H. Scheich (1982) Dendritic spine loss and enlargement during maturation of the speech control system in the mynah bird (Gracula religiosa). Neurosci. Lett. 29: 129-133.

Reeves, T. M., and O. Steward (1986) Emergence of the capacity for LTP during reinnervation of the dentate gyrus-Evidence that abnormally shaped spines can mediate LTP. Exp. Brain Res. 65: 167175.

Rutledge, L. T. (1976) Synaptogenesis: Effects of synaptic use. In Neural Mechanisms of Memory and Learning, M. Rosenzweig and E. L. Bennett, eds., pp. 329-339, MIT Press, Cambridge, MA.

Ryugo, D. K., R. Ryugo, A. Globus, and H. P. Killackey (1975) Increased spine density in auditory cortex following visual or somatic differentation. Brain Res. 90: 143-146.

Sasaki, S., J. K. Stevens, and N. Bodick (1983) Serial reconstruction of microtubular arrays within dendrites of the cat retinal ganglion cell: The cytoskeleton of a vertebrate dendrite. Brain Res. 259: 193206.

Sasaki-Sherrington, S., J. R. Jacobs, and J. K. Stevens (1984) Intracellular control of axial shape in non-uniform neurites: A serial electron microscopic analysis of organelles and microtubules in $\mathrm{AI}$ and AII retinal amacrine neurites. J. Cell Biol. 98: 1279-1290.

Schapiro, S., and K. R. Vukovitch (1970) Early experience effects upon cortical dendrites: A proposed model for development. Science 167: 292-294.

Scheibel, M. E., and A. B. Scheibel (1968) On the nature of dendritic spines. Report of a workshop. Commun. Behav. Biol. [A] 1: 231265.

Schulman, J. A. (1983) Chemical neuroanatomy of the cerebellar cortex. In Chemical Neuroanatomy, P. C. Emson, ed., pp. 209-228, Raven, New York.

Shepherd, G. M. (1979) The Synaptic Organization of the Brain, p. 364, Oxford U. P., New York.

Shepherd, G. M., and R. K. Brayton (1987) Logic operations are properties of computer-simulated interactions between excitable dendritic spines. Neuroscience 21: 151-165. 
Shepherd, G. M., R. K. Brayton, J. P. Miller, I. Segev, J. Rinzel, and W. Rall (1985) Signal enhancement in distal cortical dendrites by means of interactions between active dendritic spines. Proc. Natl. Acad. Sci. USA 82: 2192-2195.

Sotelo, C. (1973) Permanance and fate of paramembranous synaptic specializations in "mutants" and experimental animals. Brain Res. 62: $345-351$.

Sotelo, C. (1975a) Dendritic abnormalities of Purkinje cells of neurologic mutant mice (weaver and staggerer). Adv. Ncurol. 12: 353360.

Sotelo, C. (1975b) Anatomical physiological and biochemical studies of the cerebellum from mutant mice. II. Morphological study of cerebellar cortical neurons and circuits in the weaver mouse. Brain Res. 94: $19-44$.

Spacek, J. (1985) Three-dimensional analysis of dendritic spines. II. Spine apparatus and other cytoplasmic components. Anat. Embryol. 171: 235-243.

Spacek, J., and M. Hartman (1983) Three dimensional analysis of dendritic spines. I. Quantitative observations related to dendritic spines and synaptic morphology in cerebral and cerebellar cortices. Anat. Embryol. 167: 289-310.

Stevens, J. K. (1980) Reconstructing neuronal microcircuitry: Using computers to assemble three dimensional structures from montages of serial electron microscopy. Bull. Microsc. Soc. Can. 8: 4-12.

Stevens, J. K., and J. Trogadis (1984) Computer assisted reconstruction from serial electron micrographs: A tool for systematic study of neuronal form and function. Annu. Rev. Neurobiol. 5: 341-369.

Stevens, J. K., T. Davis, N. Friedman, and P. Sterling (1980) A systematic approach to reconstructing microcircuitry by electron microscopy of serial sections. Brain Res. Rev. 2: 265-293.

Stevens, J. K., J. Trogadis, and R. J. Jacobs (1988) Development and control of axial neurite form: A serial electron microscopic analysis. In Intrinsic Determinants of Neuronal Form, R. Lasek and M. M. Black, eds., Liss, New York.

Stone, T. W. (1979) Glutamate as the neurotransmitter of cerebellar granule cells in the rat: Electrophysiological evidence. Br. J. Pharmacol. 66: 291-296.

Taveres, M. A., M. M. Paula-Barbosa, and E. G. Gray (1983) Dendritic spine plasticity and chronic alcoholism in rats. Neurosci. Lett. 42: 235-238.

Thompson, R. F. (1986) The neurobiology of learning and memory. Science 233: 941-947.

Turner, D. A. (1984) Conductance transients onto dendritic spines in a segmental cable model of hippocampal neurons. Biophys. J. 46: 8596.

Valverde, F. (1971) Rate and extent of recovery from dark rearing in the visual cortex of the rat. Brain Res. 33: 1-11.

Van Harreveld, A., and E. Fifkova (1975) Swelling of dendritic spines in the fascia dentata after stimulation of the perforant fibers as a mechanism of post-tetanic potentiation. Exp. Neurol. 49: 736-749.

Vrensen, G., and J. N. Nunes-Cardozo (1981) Changes in size and shape of synaptic connections after visual training: An ultrastructural approach of synaptic plasticity. Brain Res. 218: 79-97.

Wenzel, J., C. Schmidt, G. Duwe, W. G. Skrebitz, and I. Kudrjats (1985) Stimulation-induced changes of the ultrastructure of synapses in hippocampus following posttetanic potentiation. J. Hirnfor. 26: 573-583.

Westrum, L. E., and T. W. Blackstad (1962) An clcctron microscopic study of stratum radiatum of the rat hippocampus (Regio superior, CA1) with particular emphasis on synaptology. J. Comp. Neurol. 119: 281-309.

Westrum, L. E., D. H. Jones, E. G. Gray, and J. Barron (1980) Microtubules, dendritic spines and spine apparatuses. Cell Tissue Res. 208: 171-181.

Wilson, C. J. (1984) Passive cable properties of dendritic spines and spinyneurons. J. Neurosci. 4: 281-297.

Wilson, C. J., P. M. Groves, S. T. Kitai, and J. C. Linder (1983) Threedimensional structure of dendritic spines in rat striatum. J. Neurosci. 3: 383-398. 